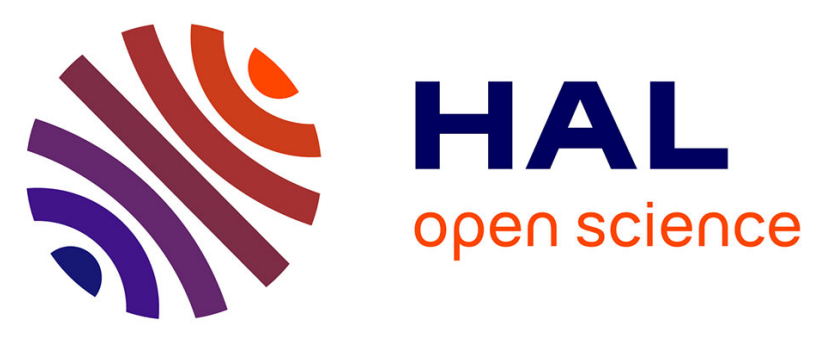

\title{
Design of membrane cascades according to the method of McCabe-Thiele: An organic solvent nanofiltration case study for olefin hydroformylation in toluene
}

A. Lejeune, M. Rabiller-Baudry, T. Renouard

\section{- To cite this version:}

A. Lejeune, M. Rabiller-Baudry, T. Renouard. Design of membrane cascades according to the method of McCabe-Thiele: An organic solvent nanofiltration case study for olefin hydroformylation in toluene. Separation and Purification Technology, 2018, 195, pp.339-357. 10.1016/j.seppur.2017.12.031 . hal01695558

HAL Id: hal-01695558

https://hal-univ-rennes1.archives-ouvertes.fr/hal-01695558

Submitted on 25 Apr 2018

HAL is a multi-disciplinary open access archive for the deposit and dissemination of scientific research documents, whether they are published or not. The documents may come from teaching and research institutions in France or abroad, or from public or private research centers.
L'archive ouverte pluridisciplinaire HAL, est destinée au dépôt et à la diffusion de documents scientifiques de niveau recherche, publiés ou non, émanant des établissements d'enseignement et de recherche français ou étrangers, des laboratoires publics ou privés. 
submitted to Separation and Purification Technology, July 2017 - Revised version 15/12/17

DESIGN OF MEMBRANE CASCADES ACCORDING TO THE METHOD OF MCCABETHIELE: AN ORGANIC SOLVENT NANOFILTRATION CASE STUDY FOR OLEFIN HYDROFORMYLATION IN TOLUENE.

Antoine LEJEUNE, Murielle RABILLER-BAUDRY*, Thierry RENOUARD

Univ Rennes, CNRS, ISCR (Institut des Sciences Chimiques de Rennes) - UMR 6226, F-35000 Rennes, France.

*Corresponding author: murielle.rabiller-baudry@univ-rennes1.fr

\section{Highlights}

- Adaptation and use of the McCabe-Thiele method for the design of membrane cascades

- Membrane cascades with recycling for the separation of a binary mixture

- Membrane cascade design for components of intermediate rejections

- Membrane cascade design for components in highly different concentrations

- Application to the case study of OSN of an olefin hydroformylation medium 


\section{Graphical abstract}

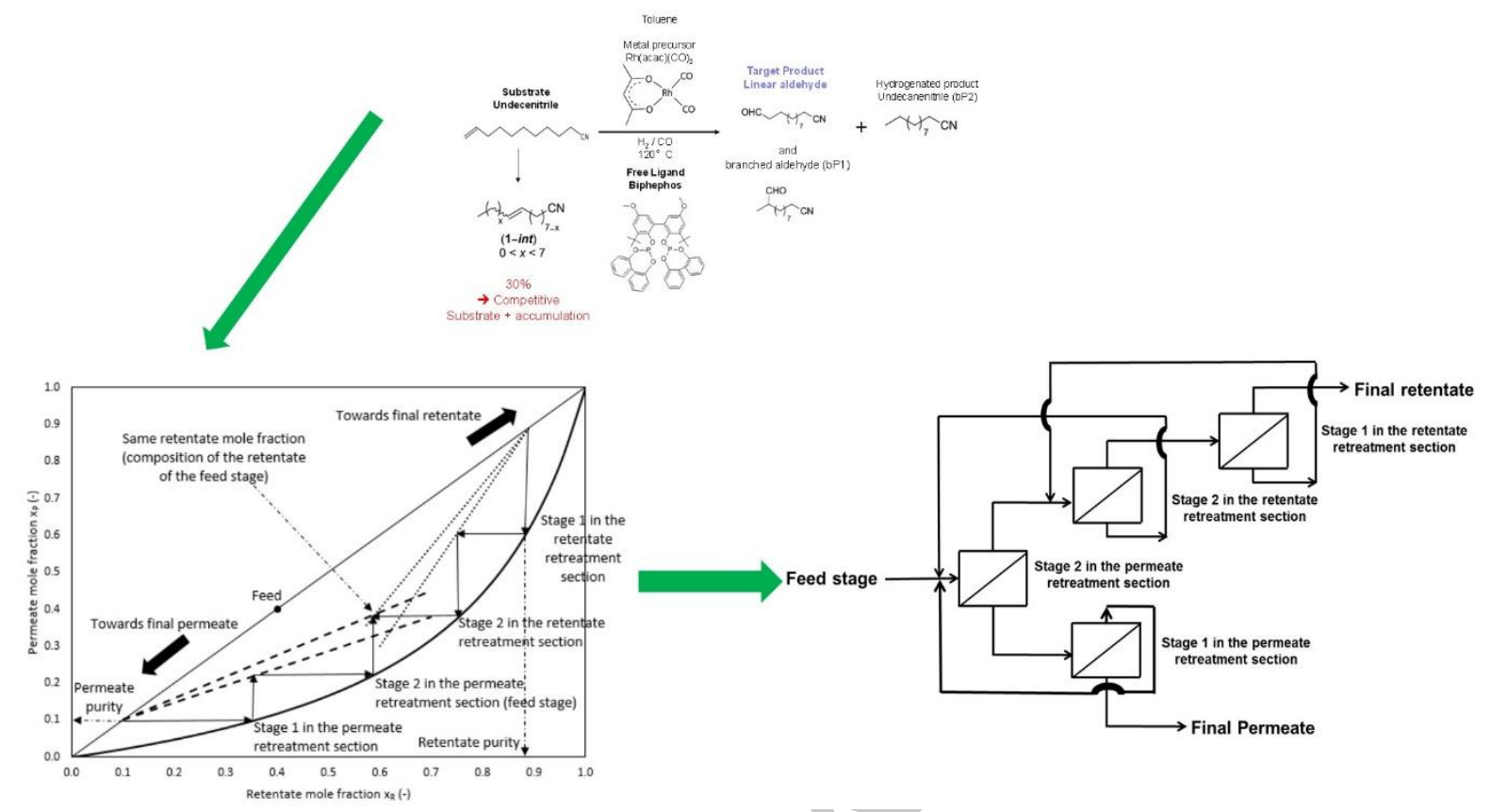




\section{ABSTRACT}

The method of McCabe-Thiele is widely used for the design of distillation columns. At a given pressure, this graphical method is only based on 3 equations: (i) the partitioning curve linking the liquid and gas phases for a given component at a given plate thanks to a unique set of thermodynamic data and (ii) two operating lines, each one describing the liquid/gas equilibrium of two consecutive plates either in the enrichment section or in the stripping one. In this paper, the method has been adapted to the membrane separation processes aiming at the easy selection of a first set of appropriate designs of cascades that fulfill given separation targets, especially in the case of a binary mixture of components having both intermediate rejections and very different concentrations. Membrane cascades involying several recyclings of the permeate and retentate streams are proposed according to a similar but more sophisticated methodology than for distillation, since for a selected membrane and for given hydrodynamic conditions (pressure, velocity, temperature), several proposals can be made for each equation mentioned above. In short, a set of operating lines is generated varying with the volume reduction ratio (VRR) either for the permeate or the retentate retreatment sections. The method is applied to the OSN separation of a final synthesis medium of a homogeneous catalysed reaction, namely olefin hydroformylation achieved in toluene. This example is a typical one dealing with the more general case of a product to be extracted in the permeate and a catalytic system to be recovered in the retentate for further recycling in the synthesis reactor aiming at a greener production process. The initial concentration ratio of the two components to separate in OSN is $1 / 1000$ and both compounds have intermediate rejections of $30 \%$ and $88 \%$. Thanks to this method, the design of several membrane cascades is proposed and discussed according to different goals of separation (target product purity or recovery, enrichment of component to be recycled, energy consumption, etc.).

\section{KEYWORDS}

Membrane cascade with recycling, membrane cascade design, McCabe-Thiele method, continuous process, organic solvent nanofiltration, olefin hydroformylation in toluene 


\section{Introduction}

Organic Solvent Nanofiltration (OSN) is a recent separation process with many possible applications in fine chemistry especially for the recycling of homogeneous catalysts [1-19], in the pharmaceutical industry $[\mathbf{2 0}, \mathbf{2 1}]$, in petro chemistry [22, 23] and in biotechnologies [24]. Actually, OSN is an eco-friendly process because (i) it is energy saving contrary to distillation the mainly used separation process in the organic chemistry industry, (ii) it does not involve any state change contrary to distillation and crystallization, nor solvent addition (when no diafiltration steps are required) contrary to liquid-liquid extraction. The OSN industrial development has become a reality for solvent recycling [22] but remains a challenge for multicomponent separations that are dragged by the commercial membrane selectivity often too poor to reach subtle fractionations into individual components moreover when achieved with only one filtration step.

Dealing with fine organic chemistry and media issued from homogeneous catalyzed reactions, such as olefin metathesis or substituted olefin hydroformylation $[\mathbf{1}, \mathbf{2}, \mathbf{4}, \mathbf{5}, \mathbf{1 0}-\mathbf{1 3}, \mathbf{1 9}, \mathbf{2 5}-\mathbf{3 2}]$ the components to separate have generally close molecular weights and sizes (less than 1/10 MW ratio). In one single filtration, commercial membranes based on polyimide or polydimethylsiloxane usually do not fully retain the solutes to recover in the retentate (mainly the catalytic system) and do not fully allow the products to pass through the membrane towards the permeate $[4,33,34]$.

Many studies focus on the improvement of the membrane performances thanks to (i) synthesis of original prototype membranes, this effort being time consuming [35-39], (ii) synthesis or selection of new soluble catalytic systems more retained by the membranes $[\mathbf{1 0}, \mathbf{1 2}, \mathbf{1 4}]$ and (iii) preparation of catalytic membranes or development of syntheses in a (catalytic) membrane reactor $[\mathbf{4}, \mathbf{1 1}, \mathbf{1 3}, \mathbf{4 0}]$. Besides these improvements, a better use of the commercial membranes appears as a requirement. Consequently, cascades are of growing interest to improve OSN performances thanks to commercial membranes [33, 41-44].

The principle of a membrane cascade is that the filtered solution passes consecutively through several membranes. Membranes can be chosen either similar or different (material and cutoff). Moreover, each stage can filter in a different way (especially VRR) and/or be the solvent inlet for a diafiltration purpose [34]. Addition of a recycling from one retentate or permeate to the feed stream of a previous stage, the place of which can be discussed and optimized, generally improves the cascade performances $[33,41,42]$. Figure 1 shows some illustrations of membrane cascades with or without such recycling. 


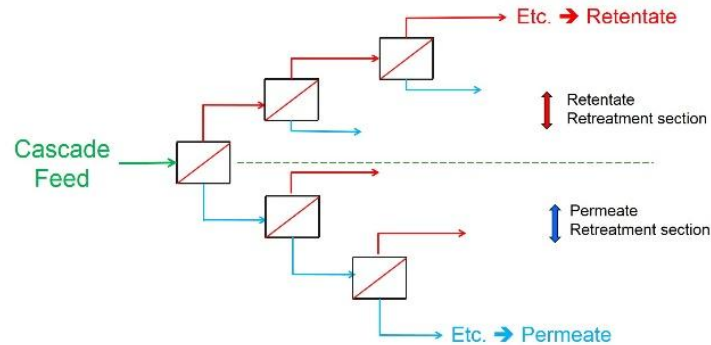

(a)

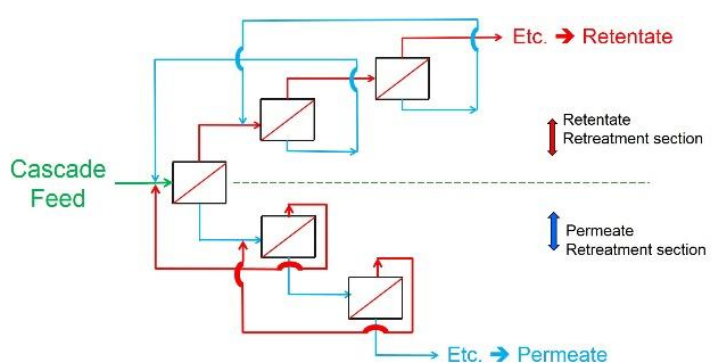

(b)

Figure 1: Examples of membrane cascades: (a) without recycling, (b) with recycling between two consecutive stages.

Among all these possibilities, the end-user can be puzzled: how to design a cascade and select the most appropriate one? Only few papers deal with this question $[\mathbf{2 3}, \mathbf{4 2}, \mathbf{4 5}]$ probably due to a lack of a perfectly clear methodology able to quickly propose an acceptable simplification of the problem. This complexity can be related to the lack of models to accurately simulate membrane performances (flux and selectivity) for the separation of multicomponent media, but also to the lack of methodology to model membrane cascades themselves starting from a set of experimental data obtained at lab-scale.

A first approach can be to imagine a systematic way to design membrane cascades (choice of the membrane, maximum number of stage, imposed VRR at a given stage). Then, several calculations (recovery, purity, energy consumption, etc.) have to be performed as a first transposition of what could be an industrial equipment.

This is in agreement with the classical approach followed by several authors that explained the modelling of selected membrane cascades and performed their optimization (usually thanks to a cost optimization) in order to find the best design for a given separation. For instance Adi et al. [23] focused on the separation of a mixture of hydrocarbons and Abejón et al. [42] optimized a membrane cascade for the purification of a solute from its impurity in methanol. Other authors highlighted laboratory scale experiments and focused on the feasibility of membrane cascades for better OSN performances [41-49].

Nevertheless, a literature review shows that there is still a lack of conceptual methodology to design efficient membrane cascades, except the first attempts based on the adaptation of the well-known McCabe-Thiele graphical method formerly proposed in 1925 for distillation and nowadays widely used for column design [50]. This method is usually used in order to find the number of theoretical plates in a distillation column and has been previously used for liquid-liquid extraction [50-52]. As for other separation processes, the graphical method of 
McCabe-Thiele has been recently envisaged to design membrane cascades according to targeted separations (purity, recovery), but remains rarely applied in the membrane science.

In 1965, Hwang and Kammermeyer [53] explained the principles of the general case of cascade operations for a binary separation (mass balances and equations) but they did not use it for a real case study. Some years after, they suggested to apply it for the separation of gases [54]. In 1992, Keurentjes et al. [55] also used the method of McCabe-Thiele for the separation of water and 1,3-butanediol by reverse osmosis and optimized their cascade by minimizing the membrane area.

An attempt to use this approach was logically proposed for pervaporation, a membrane process related to distillation for which a phase change occurs during the separation, in order to compare pervaporation and distillation performances. Nevertheless, no build-up way was shown to explain how to obtain the cascades $[\mathbf{5 6}, \mathbf{5 7}]$.

In 2011, Vanneste et al. [45] were the only ones for a long time to use the method of McCabeThiele for the membrane separation of a liquid medium and binary systems. In addition to the use of the solute rejection, they defined a separation factor allowing dealing with the behavior of two solutes at the same time. They predicted the design of membrane cascades for the separation of different sugars in water nanofiltration. The membrane cascades were then compared to the usual simulated moving bed chromatography to show the possible advantages of membrane separation thanks to an advantageous cost analysis. However, a sensitivity analysis of the adapted method of McCabe-Thiele and a detailed explanation of the reading of the diagrams were not given because it was out of the scope of the paper.

More recently, in 2013, Siew et al. [34, 41] proposed a simplified approach of the McCabeThiele method to understand the influence of the addition of stages on the purity and concentration of an active pharmaceutical ingredient (API) recovered by OSN. They first concentrated an API in ethyl acetate/methanol (90/10) thanks to a three-stage membrane cascade and succeeded to increase its overall "rejection" from $55 \%$ for a single pass to $80 \%$ with the cascade [41]. Then they studied the purification of an API from its reagent in excess, always with a three-stage membrane cascade but with the addition of diafiltration. Despite the close rejection of the two solutes (99\% for the API and $90 \%$ for the reagent), an efficient purification was achieved with the cascade [34]. This adaptation of the McCabe-Thiele method to OSN dealt with the separation of two components in the particular case where one solute is almost fully retained in the retentate whereas the other one is only partly transmitted in the permeate. 
The study shown in the present paper aims at detailing the use of the McCabe-Thiele method adapted for OSN separation. The fundamental differences with the original method proposed for distillation are highlighted with the general case of a mixture made of several components that are all characterized by intermediate rejections varying with concentrations. We propose a way of simplification to initially design the membrane cascades on the basis of the separation of the two most difficult components to separate, namely the less retained component to recover in the retentate and the less transmitted component to collect in the permeate. The principles, assumptions and equations as well as the necessary experimental data are given and explained, and a sensitivity analysis of the cascade designs is proposed. For sake of illustration, the chosen OSN case is that of a substituted olefin hydroformylation media in toluene.

\section{Theoretical part: Modelling and methodology of membrane cascades}

As already explained thanks to Figure 1, several designs can initially be proposed. For sake of efficiency and due to the target application, several simplifications have to be taken into account as the starting point of the method.

\subsection{Simplifications related to the media to be filtered}

The case study corresponds to the final media of the hydroformylation of a substituted olefin (10-undecenitrile) leading to a linear aldehyde as the target product (Figure 2). This reaction is performed in presence of a syngas and a catalytic system (the metal precursor $\mathrm{Rh}(\mathrm{acac})(\mathrm{CO})_{2}$ and a biphephos ligand in excess that will be coordinated in situ to the metal precursor to give the active catalyst). OSN is performed at room temperature after degassing and cooling the reaction media down to room temperature. The media to be filtered contains all the components shown in Figure 2 except the initial substrate that is fully converted. The main goal is to retain the catalytic system for recycling, the less retained component of the catalytic system being the extra free biphephos ligand. The second goal is to extract the target product (linear aldehyde) together with all side-products. Preliminary OSN experiments have proved that there is no selectivity in the separation of all these products and that the target product to extract is not fully transmitted [47]. 
As a starting consideration, in an overall approach aiming at using only OSN for extraction, recycling and final purification, we have stated that an efficient membrane cascade would be defined such as allowing full rejection of components to be retained and complete extraction of components to be transmitted. This assumption can be considered as too excessive and might be discussed with respect of the final cost and thus might probably be revised for a more realistic global process based on coupling of OSN and distillation (but the coupled process is out of the scope of the present paper).

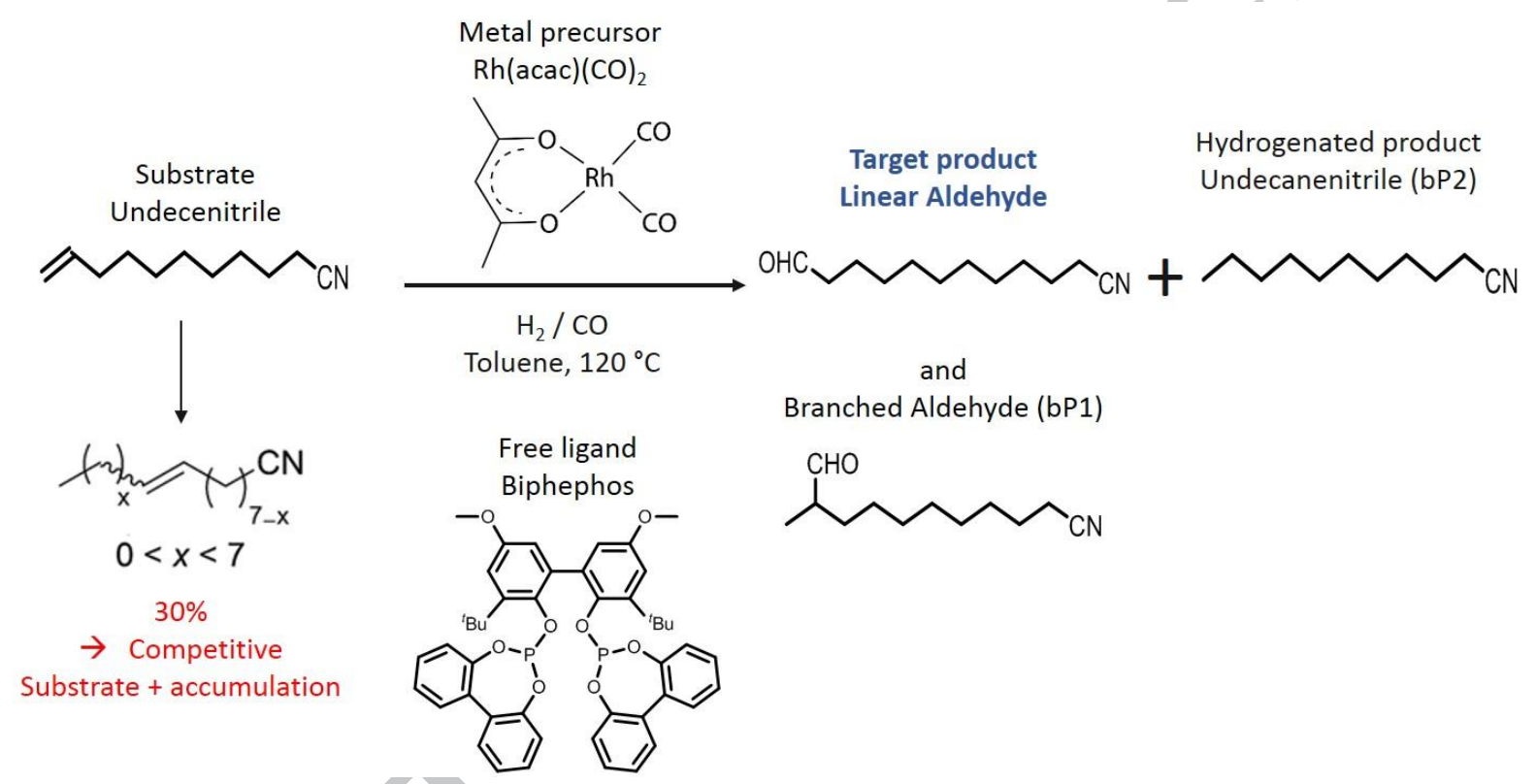

Figure 2: Reaction media to be treated in OSN thanks to membrane cascades.

With respect to our starting consideration and for sake of simplification, in a first attempt the cascade must be designed when looking only for the separation of two well selected compounds: those that are the most difficult to separate, i.e. the most retained that must be transmitted in the permeate, further called $\mathbf{A}$ and the less retained that must be recovered in the retentate, further called $\mathbf{B}$.

Since the rejections of $\mathbf{A}$ and $\mathbf{B}$ are both of intermediate levels (see the case study below), the full extraction of the target product $\mathbf{A}$ in the permeate appears difficult. Diafiltration steps can be added to enhance the extraction of $\mathbf{A}$ in the permeate. But, in this study, we voluntary avoid designs involving diafiltration because the case study deals with a toluene media. Toluene is not an eco-friendly solvent but cannot be easily replaced by a greener one. We prefer to recycle the maximum of solvent between each stage in order to minimise the overall toluene consumption. A strategy of full recycling of intermediate streams has been chosen 
allowing only one global retentate outlet and one global permeate outlet for the cascade (Figure 1-b). We can consider that the recycling of toluene achieved by this way acts as a kind of pseudo-diafiltration except the fact that the added solvent is not pure.

The arising question is then the recycling position. For sake of minimization of the membrane filtering area and pumping energy [45] for each stage we have a priori considered that the recycling must be done from one stage to the previous one and not to other stages, but this choice can be questioned [48].

Our last simplification is due to the lack of commercial membranes able to filter such media in toluene. We assume that all stages of the cascade use the same reference membrane. Fundamentally, it does not change the methodology and the general equations to play with, but the number of figures allowing the McCabe-Thiele approach is reduced compared to a more general case study.

\subsection{General design of membrane cascades involving systematic intermediate recycling}

The membrane cascade objective is to retreat the permeate and retentate of the feed stage by adding other membranes. Generally speaking, in a cascade, three sections can be distinguished:

(i) the feed stage

(ii) the retentate retreatment section (also called multistage section $[\mathbf{4 2}, \mathbf{4 3}]$ or stripping section $[\mathbf{4 1 , 5 8}]$ in reference to distillation)

(iii) the permeate retreatment section (also called multipass section $[\mathbf{4 2}, \mathbf{4 3}]$ or enrichment section $[\mathbf{4 1 , 5 8}]$ in reference to distillation).

In the retentate (respectively permeate) retreatment section, the permeate (respectively retentate) of a given stage is recycled towards the feed of the previous stage. This design is usually called membrane cascade with recycling (or counter-current cascade [33, 34], Figure 1-b, Figure 3). Note that in the following, as a convention in this paper, the feed stage will always be considered as part of the permeate retreatment section (see below).

Figure 3-a shows the analogy between distillation and a membrane cascade with recycling, both of them leading to only two outlet streams. 


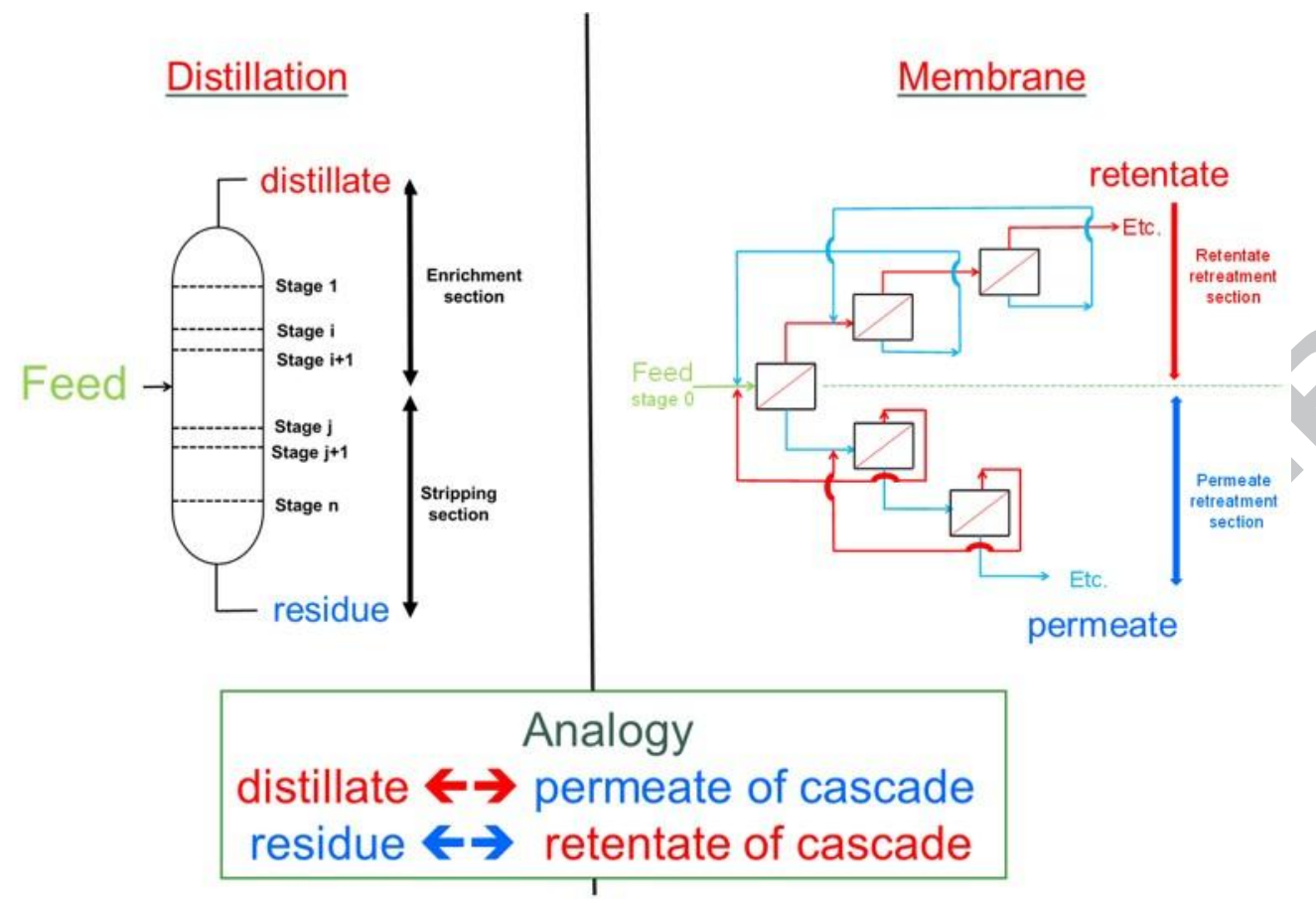

(a)

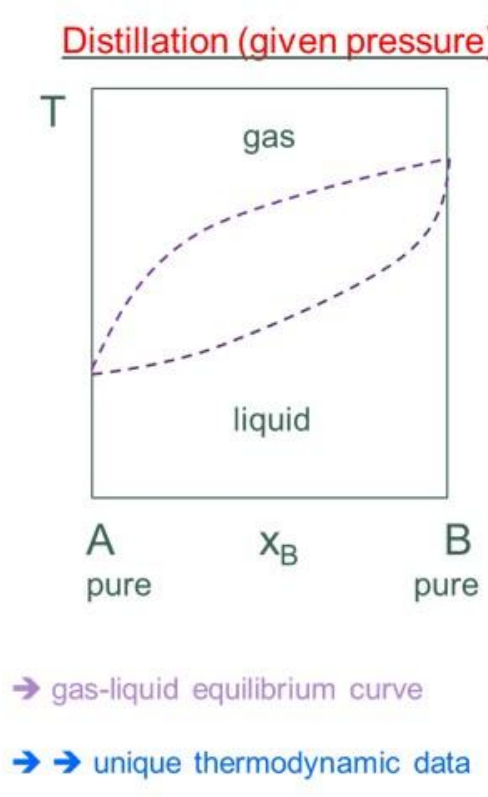

(b)

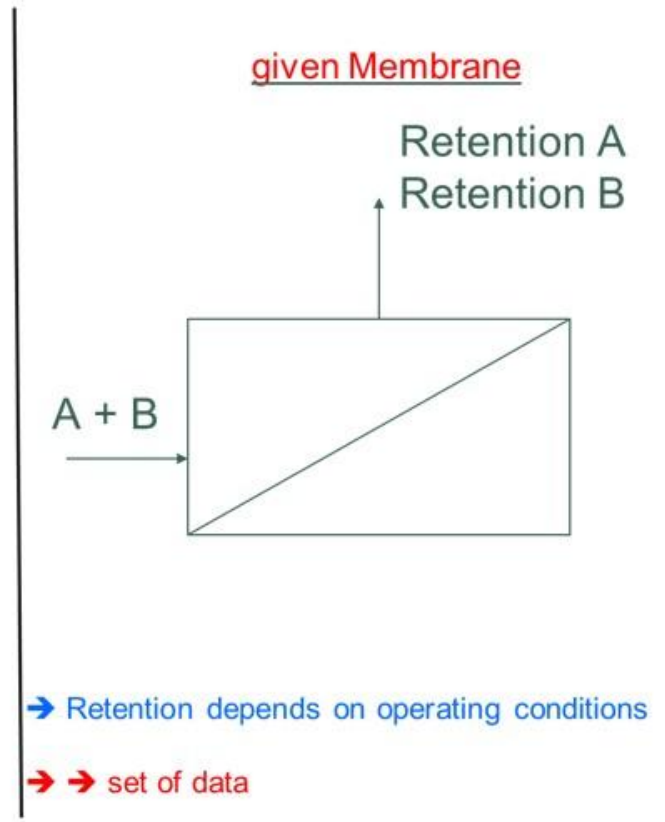

(c)

Figure 3: Comparison between distillation and a membrane cascade with recycling between two consecutive stages - (a) analogy - Input data for McCabe-Thiele methods - (b) distillation for which a single set of thermodynamic data is required - (c) membrane cascade for which choices must be done at start because of the membrane separation complexity. 


\subsection{Graphical method of McCabe-Thiele}

In this part, the McCabe-Thiele method for distillation will be briefly presented for sake of clarity to introduce in a clearer way the adaptations required for membranes.

\subsubsection{Assumptions and first choices}

Similar assumptions are needed for the distillation and the membrane cascade methods. In both cases we only consider separation of a binary mixture as already mentioned above.

The feed of the process is known, namely the initial concentration of the two solutes. The feed flow is not required but can be used for further analysis of the pertinence of the cascade design. Both processes are continuous and have reached their steady-state conditions.

Finally, for distillation, at a given pressure only one thermodynamic set of data is used (Figure 3-b). For membrane cascade, a constant rejection is assumed for further simulations over the concentration ranges. It is not so easy nor probable to experimentally fulfill such requirements because membrane performances depend on several parameters such as the temperature, transmembrane pressure, mixture composition and concentration, and hydrodynamics (Figure 3-c).

Note that, in the following, all rejections are obtained with one selected membrane running at a given transmembrane pressure (TMP) but also in a given physico-chemical environment (temperature, mixture composition and concentration) and in given hydrodynamic conditions (cross-flow velocity especially). This point is the first fundamental difference between distillation and membranes. To draw realistic membrane cascades from such approach, we consider that the rejections must be chosen at the "optimal TMP". This optimal TMP is that for which the difference between $\mathbf{A}$ and $\mathbf{B}$ rejections is the greater one, together with another requirement dealing with $\mathbf{B}$ which has to be sufficiently retained (close to 90\%). However, it is well-known that, even at a given TMP, the rejection generally varies with the concentration of the solute itself. Moreover, the rejection also varies with the permeate flux that can be correlated to the overall concentration of several solutes belonging to the mixture and have some impact on concentration polarisation and fouling (without any synergy in transfer mechanisms of the different solutes).

A particular attention must thus be paid to the filtered mixture aiming at generalization for OSN application to media issued from homogeneously catalyzed reactions. Intrinsically the catalytic system is at very low concentration compared with that of the substrate and other 
products (a classical ratio can be close to 1/1000). Thus, for a quick choice of the cascade design the constant rejection value used for simulations must be carefully chosen. The choice is of course driven by the case study.

In this paper, we have considered that the most sophisticated cascade is obtained from simulations performed when using the higher rejection for solute $\mathbf{A}$ that is the most concentrated in the mixture and also the solute to be transmitted in the permeate. This case corresponds to the rejection obtained at low concentrations of $\mathbf{A}$ (matching with the rejection in the initial mixture feeding the membrane cascade, as experimentally measured for only one stage process [47]). In this filtered medium, at a given TMP, the rejection of solute $\mathbf{B}$ varied only a little with its concentration as well as with that of A. Consequently, the rejection of solute $\mathbf{B}$ is approximated in a fairly good way by considering that inferred from the rejection at the "optimal TMP".

\subsubsection{Strategy for transposition of the McCabe-Thiele graph used for distillation to membrane cascade application}

For sake of clarity, the method for distillation is given here before detailing transposition to membrane. The overall philosophy is first explained then the equations are detailed and discussed.

\subsubsection{Partitioning curves}

In distillation, the method works with the equilibrium thermodynamic diagram at a given pressure. These equilibrium curves have been adapted by McCabe-Thiele into a partitioning curve relating the gas mole fraction $(\mathrm{y})$ and the liquid mole fraction $(\mathrm{x})$ of the less volatile component of the binary mixture in a given plate (Figure 4-a). This way allows building distillation columns with several plates thanks to only two complementary straight lines (see below) if the assumption of Lewis is done (same mole flow in the gas and liquid fraction in the whole cascade which is a common assumption in distillation).

A quite similar plot can be obtained dealing with a membrane separation for which a partitioning curve links the permeate and the retentate of a given stage. To keep the same overall aspect of the graph, we have chosen to plot the permeate mole fraction $\left(\mathrm{x}_{\mathrm{P}}\right)$ versus the retentate mole fraction $\left(x_{R}\right)$ of the most retained component of the binary mixture in a given stage (Figure 4-b). 


\section{Distillation (given pressure)}
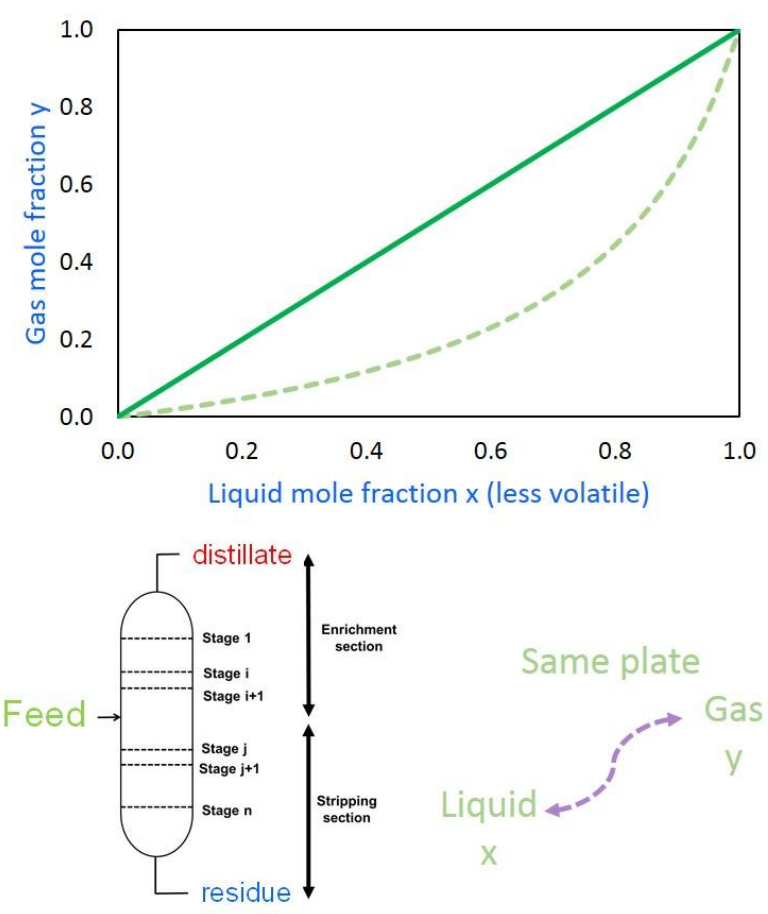

(a)
Given Membrane, TMP and hydrodynamics
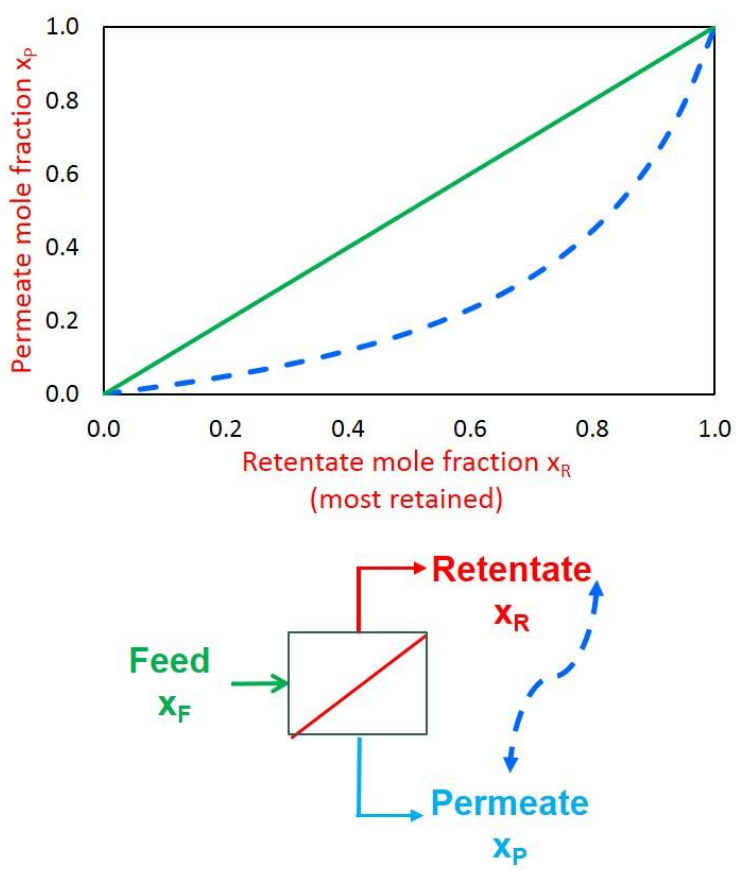

(b)

Figure 4: Partitioning curves for McCabe-Thiele methods - (a) distillation for which a single set of thermodynamic data is required - (b) membrane cascade for which choices must be done at start because of the membrane separation complexity, here in the case of a given VRR and constant rejections.

\subsubsection{Operating straight lines}

In distillation, to define the starting point of an operating line (dot on the first bisector, Figure 5-a), there is a need to define the goal to reach in terms of the final target distillate composition. Roughly, this first line is the relationship between the liquid and gas composition of two consecutive plates in the column enrichment section. Symmetrically, when defining the goal of the final residue composition, it is possible to define a second operating line which is the relationship between the liquid and gas composition of two consecutive plates in the column stripping section (Figure 5-b).

For membrane transposition, two types of operating lines can also be defined. The first type is based on the relationship between the permeate mole fraction of a given stage $\left(\mathrm{x}_{\mathrm{P}, \text { stage }}\right)$ versus the retentate mole fraction $\left(\mathrm{x}_{\mathrm{R}, \mathrm{stage}}\right)$ of the most retained component of the binary mixture between two consecutive stages in the permeate retreatment section (Figure 5-c). The second type is symmetrically defined in the retentate retreatment section (Figure 5-d). 
Distillation (given pressure)
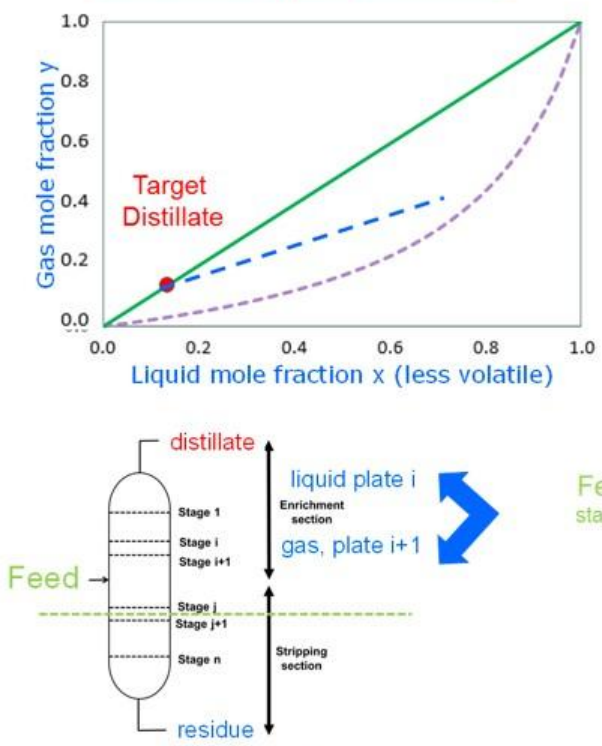

(a)
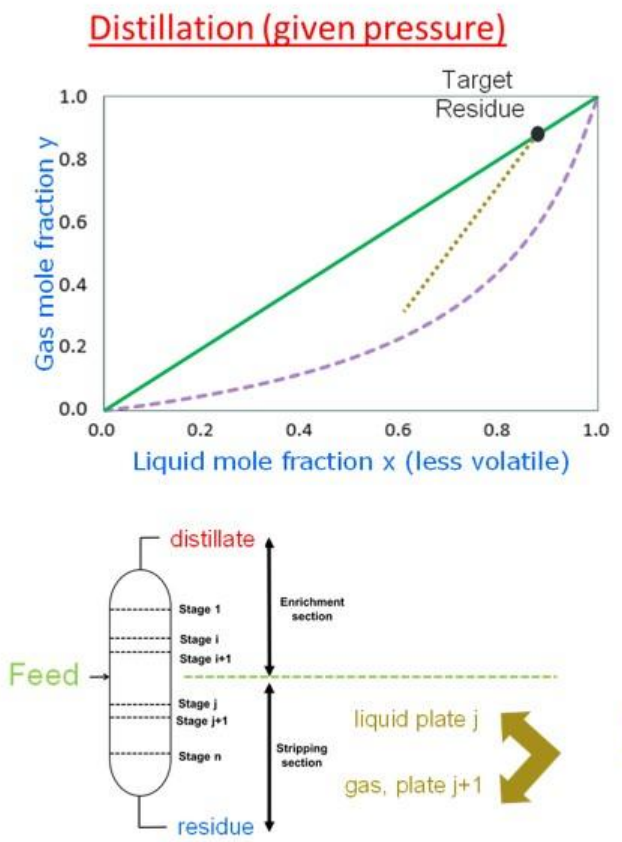

(b)
Given Membrane, TMP and hydrodynamics

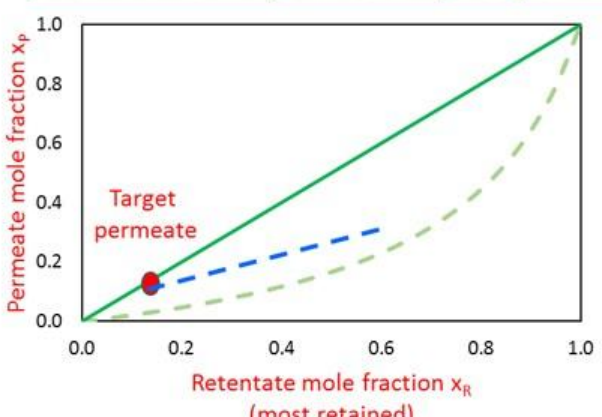

(most retained)

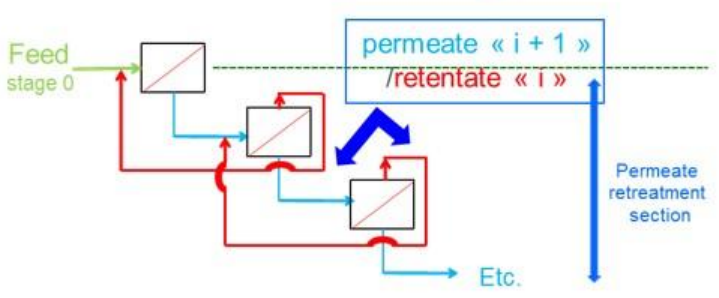

(c)

Given Membrane, TMP and hydrodynamics
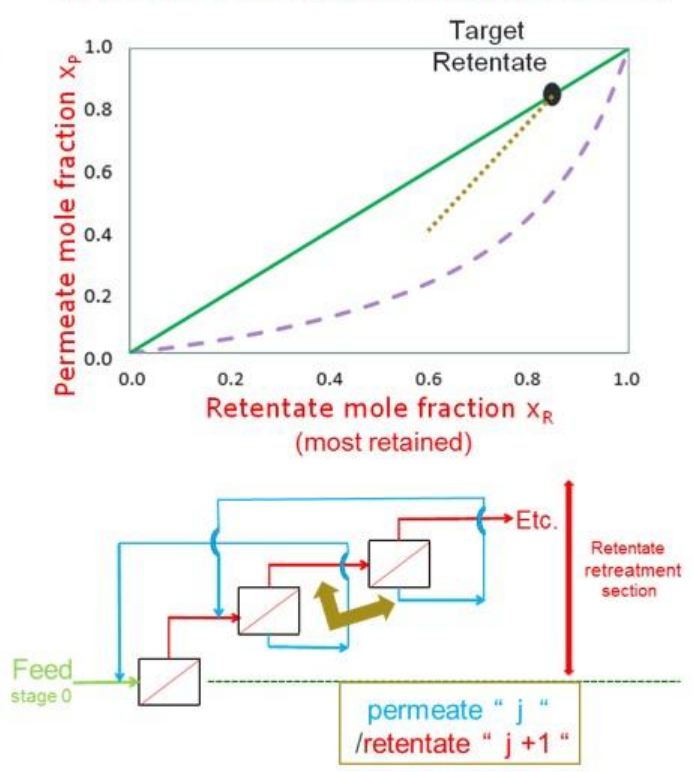

(d)

Figure 5: Partitioning curves and operating lines for McCabe-Thiele methods - (a) distillation in the enrichment section - (b) distillation in the stripping section - $(c)$ membrane

cascade in the permeate retreatment section in the case of a given VRR and constant rejections $-(d)$ membrane cascade in the retentate retreatment section in the case of a given $V R R$ and constant rejections.

\subsubsection{Complexity of McCabe-Thiele graph for membrane cascades}


As mentioned above, only one thermodynamic diagram is usually used for the McCabe-Thiele graph in distillation leading to a simple figure based on one partitioning curve and two operating lines (Figure 6-a). If the overall representation can be easily transposed to the membrane case, the build-up depends on the chosen VRR. A set of partitioning curves and operating lines can be used depending on the VRR (Figure 7-b) that can trigger a different cascade build-up. Note that in a real membrane cascade the concentrations generally vary from one stage to another, and consequently the rejections as well. For a cascade, the consequence is that several partitioning curves as well as operating lines will be generated. In a first attempt of simplification, the choice of constant rejections for simulation appears thus necessary to propose a first design of a cascade using this method. Note that this design will correspond to the most sophisticated cascade (kind of upper limit) that have to be discussed for a given mixture, knowing that further simplifications will be necessary. Nevertheless, even after simplification, the overall graph to play with remains quite complex; this is the second fundamental difference with the simpler distillation case. In the following, for sake of simple illustration, we added another criterion by using the same VRR for each stage of the cascade, but it does not change the set of general equations used (see below).

Distillation (given pressure)

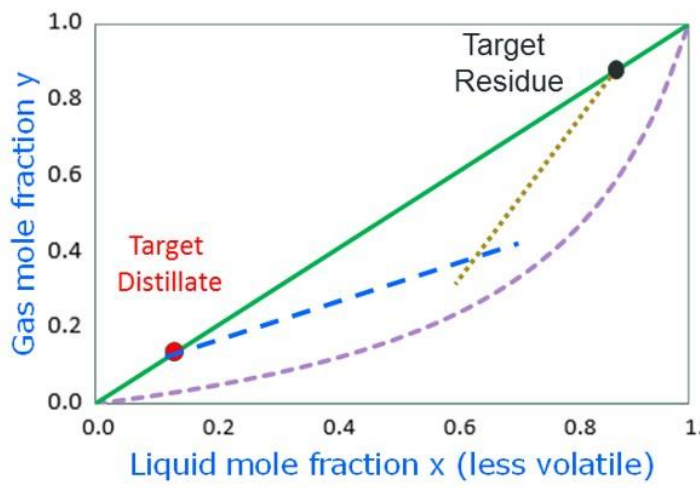

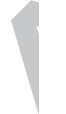

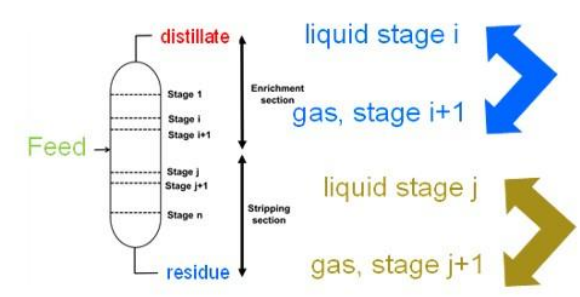

(a)

\section{Given Membrane, TMP and hydrodynamics}
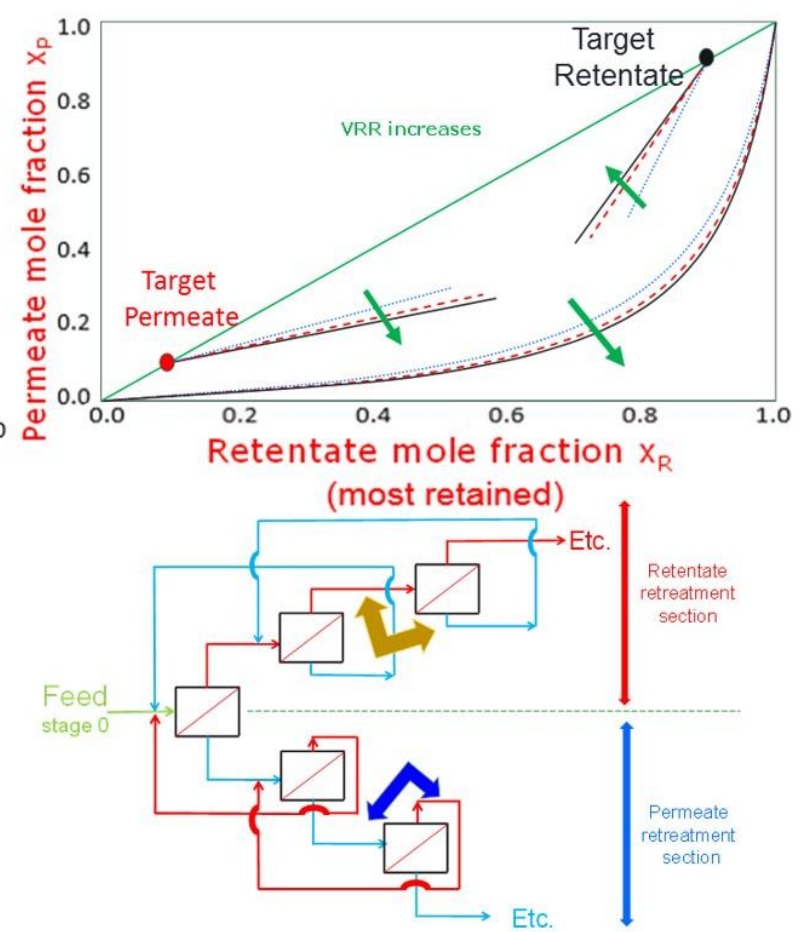

(b) 
Figure 6: Partitioning curves and operating lines for McCabe-Thiele methods - (a) distillation - (b) membrane cascade highlighting the impact of VRR variation on each curves/lines for a given stage and constant rejections.

\subsubsection{Equations of McCabe-Thiele diagram for membrane cascades}

Equations allowing the calculations of partitioning curves and operating lines are given below.

\subsubsection{Parameters and necessary (experimental) data to run the method}

The rejection (Ret) of each solute is the only experimental data necessary to run the method of McCabe-Thiele. It is an instantaneous data which gives the percentage of solute retained by the membrane:

Ret $=1-\frac{C_{P(t)}}{C_{R(t)}}$

With

$\mathrm{C}_{\mathrm{R}(\mathrm{t})}$ the retentate concentration at $\mathbf{t}$ time and $\mathrm{C}_{\mathrm{P}(\mathrm{t})}$ the permeate concentration at $\mathbf{t}$ time.

But, it must be underlined that along a membrane (spiral element for instance), and depending on the filtering area, a significant increase in concentration can occur. To have a better description of the overall performances on a given stage of the cascade we prefer then to express the abatement which is the percentage of the solute retained by the overall stage.

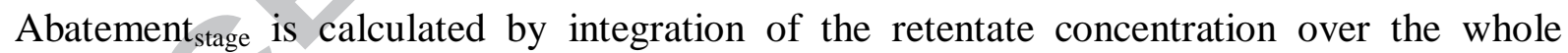
membrane [59, 60] (equation 2).

Abatement $t_{\text {stage }}=1-\frac{\overline{\mathrm{C}_{\mathrm{P}, \text { stage }}}}{\mathrm{C}_{\mathrm{F}, \text { stage }}}$

With

$\mathrm{C}_{\mathrm{F} \text {,stage }}$ the concentration of the initial feed of the stage

$\overline{\mathrm{C}_{\mathrm{P}, \text { stage }}}$ the concentration of the average permeate of the stage.

The volume reduction ratio reached on a given stage $\left(\mathrm{VRR}_{\text {stage }}\right)$ is the second parameter that is needed to run the calculation. It is the feed flowrate to the retentate flowrate ratio for a given stage: 
$\mathrm{VRR}_{\text {stage }}=\frac{\mathrm{Q}_{\mathrm{F}, \text { stage }}}{\mathrm{Q}_{\mathrm{R}, \text { stage }}}$

With

$\mathrm{Q}_{\mathrm{F}, \text { stage }}$ the feed flowrate of the stage

$\mathrm{Q}_{\mathrm{R} \text {,stage }}$ the retentate flowrate of the stage.

Note that $\mathrm{VRR}_{\text {stage }}$ is different from the overall VRR reachable by the entire cascade. In the following and for sake of simplicity, it is assumed that the same volume reduction ratio $\left(V_{R R} R_{\text {stage }}\right)$ is applied to each stage of the cascade. It is thus noted VRR without any other precision.

\subsubsection{Partitioning curves}

The partitioning curve links the permeate mole fraction $\mathrm{x}_{\mathrm{P}, \text { stage }}$ and the retentate mole fraction $\mathrm{x}_{\mathrm{R}, \mathrm{stage}}$ of a compound at a given stage (Figure 7-a). The basic equation for the partitioning curve depends on the separation factor $\alpha_{\text {stage }}$ according to equation $4[\mathbf{4 5}, \mathbf{5 3}]$.

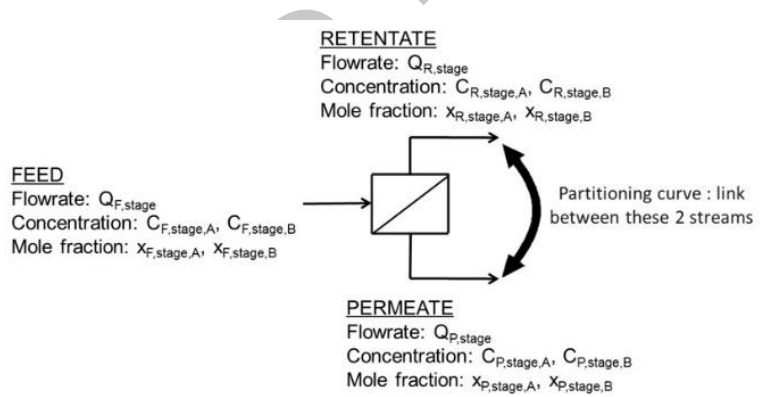

(a)

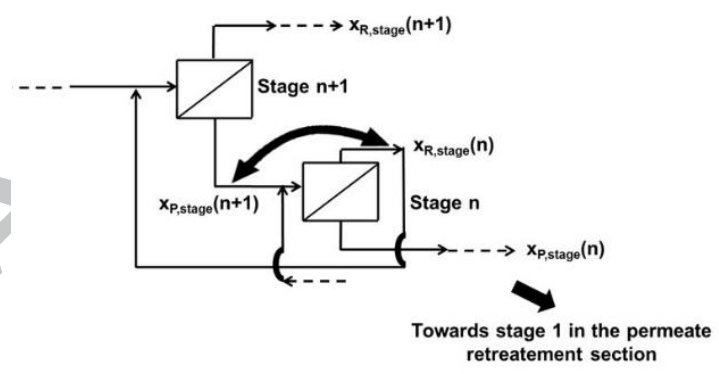

(b)

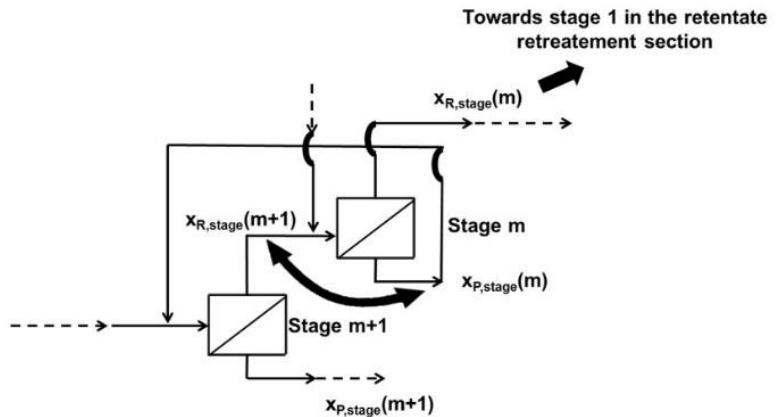

(c)

Figure 7: Relationships between mole fractions.

(a) one-stage process and meaning of the partitioning curve (equation 4) - $\boldsymbol{A}$ and $\boldsymbol{B}$ refer to the 2 solutes to separate. Outline of two stages: $(b)$ in the permeate retreatment section - the double arrow refers to the meaning of the operating lines in the permeate retreatment section (equation 9) - (c) in the retentate retreatment section - the double arrow refers to the meaning of the operating lines in the retentate retreatment section (equation 13). 
$\alpha_{\text {stage }}=\frac{\frac{x_{P, \text { stage }}}{1-x_{P, \text { stage }}}}{\frac{x_{R, \text { stage }}}{1-x_{R, \text { stage }}}}$

With, for solute $\mathbf{B}$

$\mathrm{X}_{\mathrm{P}, \text { stage, } \mathrm{B}}$ the permeate mole fraction (equation 5)

$\mathrm{X}_{\mathrm{R}, \text { stage, } \mathrm{B}}$ the retentate mole fraction (equation 6)

$\mathrm{x}_{\mathrm{P}, \text { stage }, \mathrm{B}}=\frac{\mathrm{Q}_{\mathrm{P}, \text { stage }} \times \mathrm{C}_{\mathrm{P}, \text { stage } \mathrm{B}}}{\mathrm{Q}_{\mathrm{P}, \text { stage }} \times \mathrm{C}_{\mathrm{P}, \text { stage }, \mathrm{B}}+\mathrm{Q}_{\mathrm{P}, \text { stage }} \times \mathrm{C}_{\mathrm{P}, \text { stage }, \mathrm{A}}}$

$\mathrm{x}_{\mathrm{R}, \text { stage }, \mathrm{B}}=\frac{\mathrm{Q}_{\mathrm{R}, \text { stage }} \times \mathrm{C}_{\mathrm{R}, \text { stage }, \mathrm{B}}}{\mathrm{Q}_{\mathrm{R}, \text { stage }} \times \mathrm{C}_{\mathrm{R}, \text { stage }, \mathrm{B}}+\mathrm{Q}_{\mathrm{R}, \text { stage }} \times \mathrm{C}_{\mathrm{R}, \text { stage }, \mathrm{A}}}$

With

$\mathrm{Q}_{\mathrm{P}, \text { stage }}$ and $\mathrm{Q}_{\mathrm{R}, \text { stage }}$ respectively the permeate and retentate flowrates of the stage,

$\mathrm{C}_{\mathrm{P}, \text { stage,A }}$ and $\mathrm{C}_{\mathrm{R}, \text { stage, } \mathrm{A}}$ respectively the permeate and retentate concentrations of the stage for solute A,

$\mathrm{C}_{\mathrm{P}, \text { stage, } \mathrm{B}}$ and $\mathrm{C}_{\mathrm{R}, \text { stage, } \mathrm{B}}$ respectively the permeate and retentate concentrations of the stage for solute B.

The separation factor $\left(\alpha_{\text {stage }}\right)$ can be expressed independently of the mole fraction by:

$\alpha_{\text {stage }}=\frac{\left(1-\text { Abatement }_{\text {stage }, \mathrm{B}}\right)}{\left(1-\text { Abatement }_{\text {stage }, \mathrm{A}}\right)} \times \frac{\left[1-\left(1-\frac{1}{\text { VRR }_{\text {stage }}}\right) \times\left(1-\text { Abatement }_{\text {stage }, \mathrm{A}}\right)\right]}{\left[1-\left(1-\frac{1}{\text { VRR }_{\text {stage }}}\right) \times\left(1-\text { Abatement }_{\text {stage }, \mathrm{B}}\right)\right.}$

The separation factor depends on the abatement (equation 8) $[\mathbf{5 8}, \mathbf{5 9}]$.

Abatement $_{\text {stage }}=1-\frac{1}{1-\frac{1}{\mathrm{VRR}_{\text {stage }}}} \times\left[1-\left(\frac{1}{\mathrm{VRR}_{\text {stage }}}\right)^{(1-\mathrm{Ret})}\right]$

The mole fractions in equation 4 refer in our study to the most retained solute and so $\alpha_{\text {stage }}$ is always lower than 1 . Actually, the separation factor $\alpha_{\text {stage }}$ depends on $V_{R R}$ stage as well as the 
rejection of each solutes (incorporated into the abatement). We have chosen to build the method in function of the most retained solute, so the lower is the value of $\alpha_{\text {stage }}$, the easier is the separation.

\subsubsection{Operating lines for the permeate retreatment section}

The operating lines for the permeate retreatment section link the retentate mole fraction of a stage and the permeate mole fraction of the previous stage (double arrow in Figure 7-b).

Note that the stage number index 1 deals with the stage of the final permeate leaving the cascade and so the further is the permeate from the final permeate, the higher is the index of the stage (see next paragraph dealing with the use of the McCabe-Thiele diagram).

The operating lines for the permeate retreatment section are expressed by equation 9 .

$$
\begin{aligned}
x_{P, \text { stage }}(n+1) & =\frac{\sum_{i=1}^{n}\left(\prod_{j=i}^{n} \gamma_{\text {stage }}(j)\right)}{1+\sum_{i=1}^{n}\left(\prod_{j=i}^{n} \gamma_{\text {stage }}(j)\right)} \times x_{R, \text { stage }}(n)+\frac{1}{1+\sum_{i=1}^{n}\left(\prod_{j=i}^{n} \gamma_{\text {stage }}(j)\right)} \\
& \times x_{P, \text { stage }}(1)
\end{aligned}
$$

This is the equation of a straight line and it goes by a pivot point $\mathrm{x}_{\mathrm{P}, \mathrm{stage}}(1)$, which is the mole fraction of the final permeate (target permeate, Figure 5-c).

Equation 9 depends on the stage cut $\theta_{\text {stage }}[\mathbf{4 5}, \mathbf{5 3}]$ (equation 10). The stage cut is the overall number of mole in the permeate of a stage $n_{P, \text { stage }}$ to the overall number of mole in the feed $\mathrm{n}_{\mathrm{F} \text {,stage }}$ ratio (equation 11 ). It can be calculated from equation 12 for each stage.

$\gamma_{\text {stage }}(\mathrm{j})=\frac{1-\theta_{\text {stage }}(\mathrm{j})}{\theta_{\text {stage }}(\mathrm{j})}$

With:

$\theta_{\text {stage }}(j)=\frac{n_{P, \text { stage }, A}(j)+n_{P, \text { stage }, B}(j)}{n_{F, \text { stage }, A}(j)+n_{F, \text { stage }, B}(j)}$

With:

$$
\begin{aligned}
\theta_{\text {stage }}(\mathrm{j})=(1 & \left.-\frac{1}{\operatorname{VRR}_{\text {stage }}(\mathrm{j})}\right) \times \mathrm{x}_{\mathrm{F}, \text { stage }}(\mathrm{j}) \\
\times & {\left[\left(1-\text { Abatement }_{\text {stage }, \mathrm{B}}(\mathrm{j})\right)+\left(\frac{1}{\mathrm{x}_{\mathrm{F}, \text { stage }}(\mathrm{j})}-1\right)\right.} \\
\times & \left.\left(1-\text { Abatement }_{\text {stage }, A}(\mathrm{j})\right)\right]
\end{aligned}
$$

With 
$\mathrm{x}_{\mathrm{F}, \text { stage }}(\mathrm{j})$ the feed mole fraction at stage $\mathrm{j}$.

Equation 9 highlights that there is one different operating line for each stage in the permeate retreatment section.

Hwang and Kammermeyer [53] discussed about a simplification of equation 9 in the case of a constant stage cut $\theta_{\text {stage }}$ and a constant overflow in the whole cascade, which means that the molar flow rates in the permeate and retentate of any stage are the same. In this particular case, there is only one operating line in the permeate retreatment section. This simplification is not possible in the present study because the VRR is kept constant and not the stage cut. Keeping the stage cut constant is not consistent with the usual way the membrane cascades are simulated (see for instance $[33,41-43,61]$ ).

\subsubsection{Operating lines for the retentate retreatment section}

The operating lines for the retentate retreatment section link the permeate mole fraction of a stage and the retentate mole fraction of the previous stage (double arrow in Figure 7-c). It has to be noticed that the stage number index 1 deals with the stage of the final retentate leaving the cascade and so the further from the final retentate, the higher is the index of the stage. Note that the indexes are independent between the retentate and permeate retreatment sections.

The operating lines for the retentate retreatment section are expressed by equation 13 highlighting that one different operating line is needed for each stage in the retentate retreatment section.

$$
\begin{aligned}
x_{P, \text { stage }}(m)= & \left.\frac{1+\sum_{i=1}^{n}\left(\prod_{j=i}^{n} 1 / \gamma_{\text {stage }}(j)\right.}{\sum_{i=1}^{n}\left(\prod_{j=i}^{n} 1 / \gamma_{\text {stage }}(j)\right.} \times x_{R, \text { stage }}(m+1)-\frac{1}{\sum_{i=1}^{n}\left(\prod_{j=i}^{n} 1 / \gamma_{\text {stage }}(j)\right.}\right) \\
& \times x_{R, \text { stage }}(1)
\end{aligned}
$$

This is the equation of a straight line and it goes by a pivot point $\mathrm{x}_{\mathrm{R} \text {,stage }}(1)$, which is the mole fraction of the final retentate (Figure 5-d). Equation 13 also depends on the stage cut $\theta_{\text {stage }}[\mathbf{4 5}, \mathbf{5 3}]$ (equations 10-12).

\subsubsection{Use of McCabe-Thiele diagram}

Figures 8-a and 8-b show the diagram of McCabe-Thiele dealing with distillation at a given pressure and the corresponding column design. In addition to the partitioning curve and operating lines, a last line dealing with the thermic state of the feed must be added [50]. Here 
it is assumed that the feed of the column is a vapor, so the line for the thermic state is a horizontal one passing through the first bisector and the composition of the feed of the column $[\mathbf{5 0}]$.

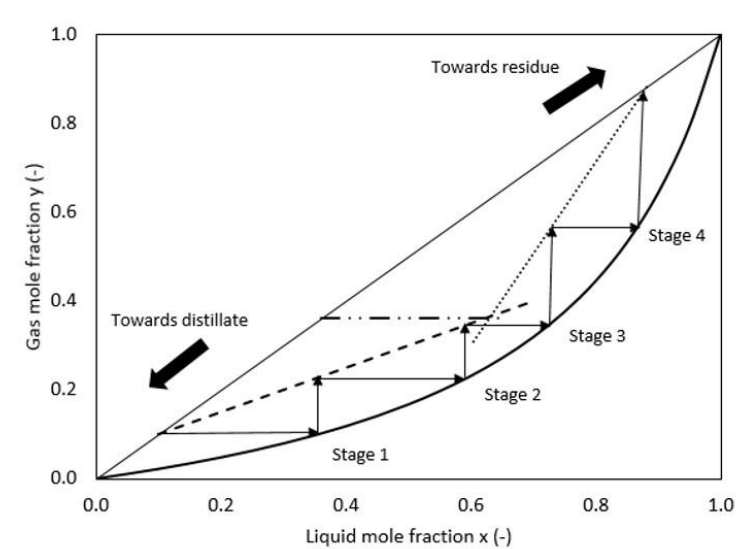

(a)

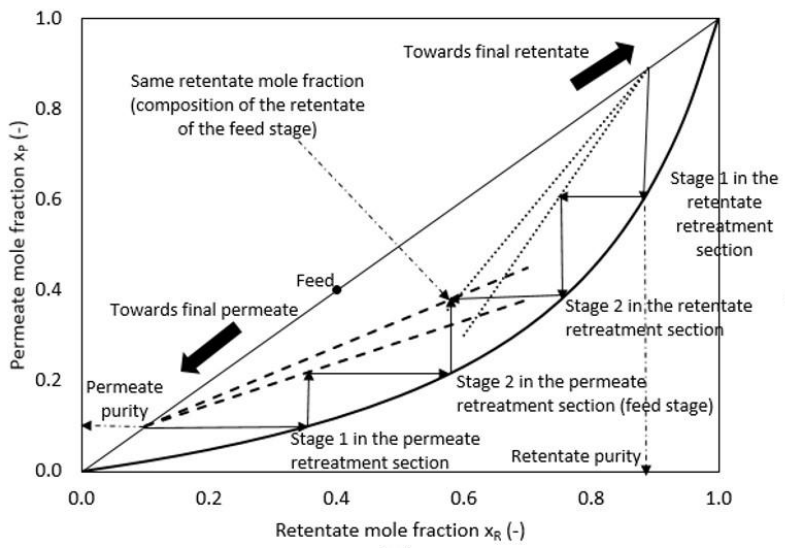

(c)

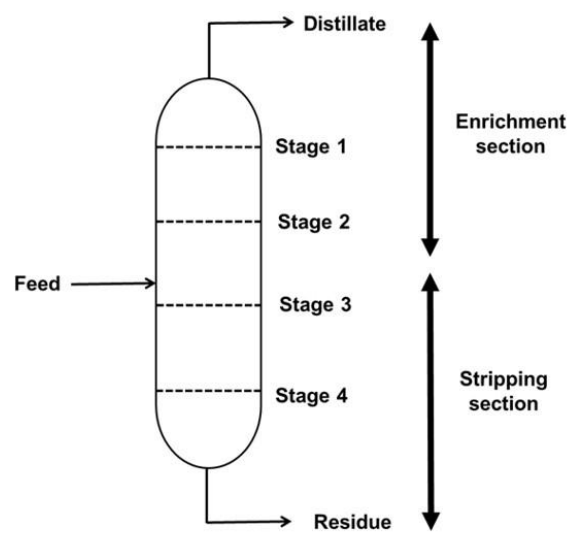

(b)

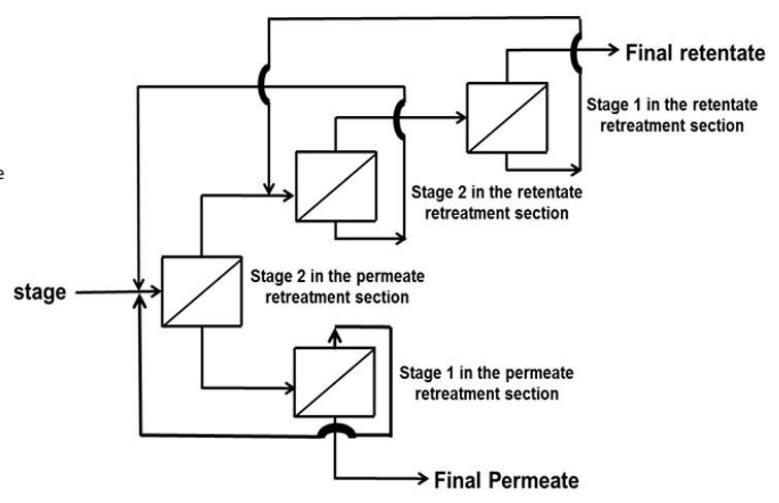

(d)

Figure 8: Method of McCabe-Thiele. For distillation: (a) (-: equilibrium curve ; - - -: operating lines for the enrichment section ; $\cdots$ : operating line for the stripping section; $\cdot .-\cdots-$ : line for the thermic state of the feed $)-(b): 4$-plate distillation column according to the corresponding diagram of McCabe-Thiele. For membrane separation: (c) (-: partitioning curve ; - - -: operating lines for the permeate retreatment section ; '...: operating lines for the retentate retreatment section ; $\bullet$ : feed cascade composition) $-(d): 4$ stage membrane cascade according to the corresponding diagram of McCabe-Thiele.

The build-up of McCabe-Thiele (Figure 8-a) starts at the lower mole fraction (target distillate, mole fraction at the top of the column but at the bottom of the diagram) and is stepped against the equilibrium curve and the operating line of the enrichment section. Once the feed mole fraction is overcame, the build-up continues on the other operating line dealing with the stripping section and moving towards the target residue. Finally, there are 4 horizontal lines meaning that the column needs 4 theoretical plates to fulfill the requirements: two in the enrichment section and two in the stripping section (Figure 8-b). 
Figures 8-c and 8-d refer to the method of McCabe-Thiele for membrane separation at given pressure and hydrodynamic conditions and a given VRR at each stage. The top of the plot goes towards the retentate and the bottom towards the permeate, which reminds the outline of Figure 1-b for the membrane cascade scheme. The mole fraction of the axes refers to the most retained solute so the partitioning curve is under the first bisector. The dot on the first bisector is the cascade feed mole fraction $\left(\mathrm{x}_{\mathrm{F}, \text { cascade }}\right)$. The lines starting from the final retentate mole fraction and the final permeate mole fraction are the operating lines for the retentate retreatment and permeate retreatment sections, respectively.

On a practical point of view, the build-up starts from the two extremities of the diagram (target retentate and target permeate):

(i) for the permeate retreatment section, it starts from the final permeate mole fraction and the build-up is stepped against the different operating lines and the partitioning curve; one has to change the operating line for each new stage. The build-up must be stopped when $\mathrm{x}_{\mathrm{R}, \text { stage }}$ overcomes the composition of the cascade feed $\left(\mathrm{x}_{\mathrm{F}, \text { cascade }}\right)$.

(ii) for the retentate retreatment section, it starts from the final retentate mole fraction and the build-up is stepped against the different operating lines and the partitioning curve. Once again, it is necessary to change the operating line for each stage. The build-up must be stopped when $x_{P, \text { stage }}$ reaches the composition of the last retentate of the permeate retreatment section which is in fact the same stream (it is the retentate of the feed stage).

In conclusion, Table 1 sums up the comparison for the use of the method of McCabe-Thiele either for distillation or membrane.

Table 1: Comparison of the McCabe-Thiele method for distillation and membrane.

\begin{tabular}{ll}
\hline \multicolumn{1}{c}{ Distillation } & \multicolumn{1}{c}{ Membrane } \\
\hline $\begin{array}{l}\text { Partitioning curve based on a thermodynamic } \\
\text { equilibrium: unique at a given pressure }\end{array}$ & $\begin{array}{l}\text { Partitioning based on the rejections: depending on } \\
\text { membrane, pressure, hydrodynamics, VRR, etc. }\end{array}$ \\
\hline $\begin{array}{l}\text { Plates: either physical or theoretical plates depending } \\
\text { on the column }\end{array}$ & $\begin{array}{l}\text { Stages: each one is a physical stage meaning that it } \\
\text { is possible to have different membranes per stage }\end{array}$ \\
\hline one operating line for the enrichment section & $\begin{array}{l}\text { Several operating lines for the permeate } \\
\text { retreatment section (one line per stage and per }\end{array}$ \\
\hline
\end{tabular}




\begin{tabular}{|c|c|}
\hline & VRR) \\
\hline one operating line for the stripping section & $\begin{array}{l}\text { A set of operating lines for the retentate } \\
\text { retreatment section (one line per stage and per } \\
\text { VRR) }\end{array}$ \\
\hline $\begin{array}{l}\text { A line for the thermic state of the feed (gas, liquid, } \\
\text { mixture gas and liquid) allowing to easily define the } \\
\text { time to change the operating lines used moving from } \\
\text { the distillate to the residue during the construction }\end{array}$ & $\begin{array}{l}\text { A pivot point }\left(\mathrm{x}_{\mathrm{F}}\right) \text { around which subtle } \\
\text { articulations have to be done allowing the design } \\
\text { to be proposed with one additional stage in the } \\
\text { permeate retreatment section and inducing the } \\
\text { need to recalculate all performances }\end{array}$ \\
\hline
\end{tabular}

\section{Experimental : Calculations}

Some details about the way to run calculations are given in the following. Besides general considerations, they sometimes depend on simplifications/adaptations that can be related to our chosen case study: 10-undecenitrile hydroformylation in toluene (Figure 2). In the ideal case of full conversion of the substrate into the target product $\mathbf{A}$, the mixture at the end of the reaction is made of (i) A to extract in the permeate and (ii) the catalytic system, to be recycled in a next batch synthesis, in the retentate. The catalytic system recyclability depends on both the recovery of the metal component and that of the extra free ligand $\mathbf{B}$ that is the less retained component of this system (experimental data, not shown). The case study can thus be restricted to a more general OSN separation of 2 solutes: $\mathbf{A}$ (product) and $\mathbf{B}$ (the "representative" component of the catalytic system,). Thanks to realistic industrial synthesis conditions, the initial concentrations are $1 \mathrm{~mol} . \mathrm{L}^{-1}$ and $10^{-3} \mathrm{~mol} . \mathrm{L}^{-1}$ for $\mathbf{A}$ and $\mathbf{B}$, respectively. These proportions are quite classical for reaction catalyzed by homogeneous (soluble) organometallic complexes for which $\mathbf{A}$ and $\mathbf{B}$ are in highly different proportions, typically the catalyst to substrate ratio is $1 / 1000$ to $1 / 100$.

\subsection{Justification of first choices to design the cascades before calculations}

With the selected PDMS membrane, in given hydrodynamic conditions, OSN has been achieved on the initial mixture in the range 10-40 bar at room temperature (details are out of the scope of this paper but can be found in [47]).

\subsubsection{Optimal TMP}

In these conditions, the "optimal" TMP is found to be 10 bar. At VRR=1, the rejections are close to $30 \%$ for $\mathbf{A}$ and $88 \%$ for $\mathbf{B}$. These experimental rejections are roughly constant over a 
wide range of VRR even if some changes are observed at highest VRRs and no synergetic effects are experimentally observed between $\mathbf{A}$ and $\mathbf{B}$ rejections. Concretely, the $\mathbf{B}$ rejection remains close to $88 \%$ and not lower than $85 \%$ whereas the A rejection progressively decreases and can become negligible. As explained in the first methodological part of this paper, we design the cascade on the basis of the higher rejection of $\mathbf{A}$ (the most concentrated and most retained component to extract in the permeate), knowing that the cascade designs generated from these assumptions would be the most complicated ones. Of course, further calculations of the real performances of the cascade have to be done in a second time for more accurate simulations.

\subsubsection{Maximum VRR}

The maximum reachable $\mathrm{VRR}_{\text {stage }}$ used in simulations is not easy to choose. At industrial scale, the limitation is generally due to the viscosity increase and/or the osmotic pressure increase that might induce a non-reasonable TMP because of the membrane material resistance and the energy consumption. In this system, it has been checked that the permeate fluxes are exclusively controlled by $\mathbf{A}$. The viscosity is quite constant when considering either a very dilute media (toluene) or a very concentrated one (pure A) meaning that this cannot be the limiting practical criterion. In pure liquid $\mathbf{A}$, the rejection decreases to zero, meaning that the osmotic pressure difference would not be a problem when increasing the $\mathrm{VRR}_{\text {stage. The }}$ real limitation can then be the rejection of $\mathbf{B}$ when increasing the concentration of $\mathbf{A}$. For sake of illustration we have decided to limit the calculations to $\mathrm{VRR}_{\text {stage }}=10$; because we guess that dead volumes and pressure drop at each stage of an industrial equipment will probably not be compatible with higher values. Table 2 sums up the initial choices made for the calculations in agreement with above justifications.

Table 2. Summary of the initial conditions for the calculations.

\begin{tabular}{cccc}
\hline Parameters & $\begin{array}{c}\text { Concentration } \\
\left(\mathbf{m o l . L}^{-\mathbf{1}}\right)\end{array}$ & $\begin{array}{c}\text { Rejection } \\
(\boldsymbol{\%})\end{array}$ & Others \\
\hline Optimal TMP & 1 & 30 & 10 bar \\
\hline A & $10^{-3}$ & 88 & 10 \\
\hline B & & \\
\hline Maximum VRR & & \\
\hline stage & for sake of simplification, same VRR at all stages are chosen as standard conditions in the following.
\end{tabular}

\subsection{Adaptation to solutes in highly different proportions}


The classical McCabe-Thiele diagrams have been systematically build-up for different VRRs up to 10, based on the conditions given in Table 2. Considering the concentrations of $\mathbf{A}$ and $\mathbf{B}$, the mole fractions are 0.999 and 0.001 , respectively. Because the mole fraction of $\mathbf{B}$ is very low, a logarithmic scale is chosen for sake of clarity (Figure 9). Such scale change has already been used for other separation processes such as solid-liquid extraction [62] but according to the best of our knowledge, never for membrane separation.

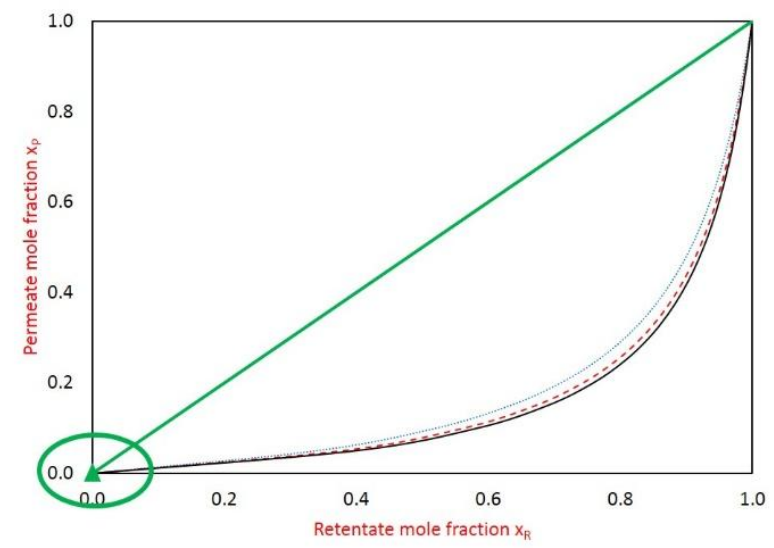

(a)

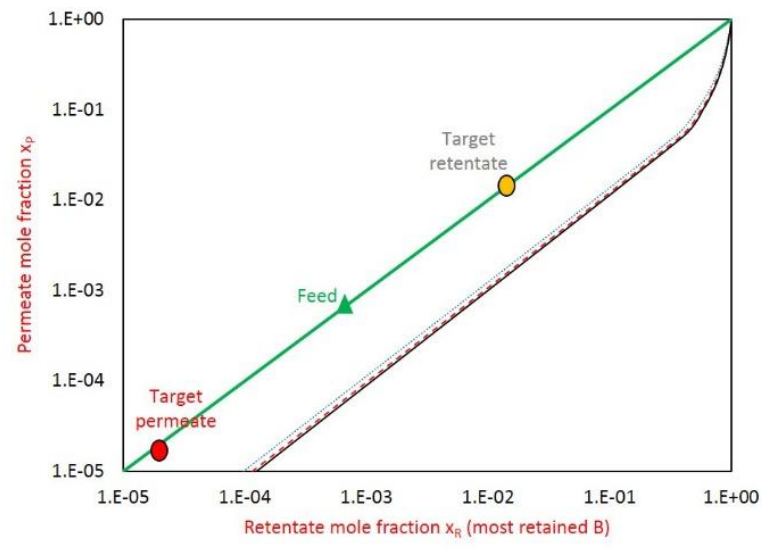

(b)

Figure 9: Scale change adapted to OSN of reactions catalyzed by homogeneous complexes (a) classical scale - (b) log-log scale.

\subsection{Iterations}

As explained in the methodological part, all curves of the McCabe-Thiele diagram can be calculated thanks to the data given in Table 1. For a given $V_{R R}$ stage, for all stages, the number of stages is not a priori defined. Consequently, one partitioning curve is calculated as well as several operating lines either in the retentate and permeate retreatment sections (anticipation of several stages). Only part of them will be useful, but it is only at the end of the build-up of the cascade that the number of really needed straight lines appears.

Of course the build-up starting from the target permeate and that starting from the target retentate (Figure 8-c) must converge if the two initial criteria are easily compatible, but that is not always the case. Thus, some adaptations are needed to always simultaneously fulfill the two criteria and converge. The method is initiated by first starting from the target permeate then building up the stages of the permeate retreatment section until the last retentate composition $\mathrm{x}_{\mathrm{R}, \text { stage(i,max1) }}$ in this section overcomes the feed composition (Figure 8-c, equation 9). Then the build-up starts back from the target retentate up to the last retentate 
composition in the retentate retreatment section $\mathrm{x}_{\mathrm{R}, \text { stage (i,max } 2)}$ (the retentate composition just before overcoming the feed mole fraction). Two cases have then been encountered:

- First case: the last retentate composition in the retentate retreatment section $\mathrm{x}_{\mathrm{R}, \text { stage(i,max2) }}$ matches exactly with $\mathrm{x}_{\mathrm{R}, \mathrm{stage}(\mathrm{i}, \max 1)}$. Thus, the design of the cascade is easily obtained and the mass balances of the whole cascade fits exactly with the targets of the separation.

- Second case: the last retentate composition in the retentate retreatment section $\mathrm{x}_{\mathrm{R}, \text { stage(i,max2) }}$ do not exactly match with $\mathrm{x}_{\mathrm{R}, \text { stage(i,max1) }}$. All the built stages have to be kept in the design of the cascade but mass balances do not perfectly fit between both sections.

The separation goals are at least fulfilled in both cases. But, the second case has been more often encountered than the first one. Accordingly, the performances of the designed cascade have to be recalculated by changing the last permeate and retentate composition in order to fit the mass balances and to propose a correct final cascade performance with some results that could be better than the initial objectives.

\subsection{Final evaluation of the cascade design according to different goals}

As already shown in this paper, the method of McCabe-Thiele allows designing membrane cascades according to different separation goals that are fixed a priori in terms of mole fraction of the target retentate and target permeate which means that they deal with purity. But generally, users prefer to discuss in terms of yields of recovery of the components without any fixed value for their purity. In this second case, the purity of the recovered components appears only as a second parameter that must be known but is not the decisive one. Depending on the goal of the separation (purity or yield of recovery), two procedures have to be used for the calculation that are explained below (Figure 10).

\subsubsection{Goal expressed in terms of purity}

If the goal of the separation is expressed in terms of purity of $\mathbf{A}$ (or $\mathbf{B}$ ) in the recovered fractions (either retentate or permeate), the calculation is easy (Figure 10-b). Purity in the target component to be recovered is expressed according to equation 14, for $\mathbf{A}$ in the permeate and equation 15, for $\mathbf{B}$ in the retentate.

Permeate purity for solute $A=\frac{Q_{P, \text { stage }}(1) \times C_{P, \text { stage }, A}(1)}{Q_{P, \text { stage }}(1) \times C_{P, \text { stage }, A}(1)+Q_{P, \text { stage }}(1) \times C_{P, \text { stage }, B}(1)}$ 
With:

$\mathrm{Q}_{\mathrm{P} \text {,stage }}(1)$ the permeate flowrate of the final stage (1) in the permeate retreatment section where the overall permeate of the cascade is recovered

$\mathrm{C}_{\mathrm{P}, \text { stage,A}}(1)$ and $\mathrm{C}_{\mathrm{P}, \text { stage, } \mathrm{B}}(1)$ the concentrations of $\mathbf{A}$ and $\mathbf{B}$, respectively, in the overall permeate of the cascade recovered on the final stage (1) in the permeate retreatment section.

Retentate purity for solute $B=\frac{Q_{R, s t a g e}(1) \times C_{R, \text { stage, } B}(1)}{Q_{R, \text { stage }}(1) \times C_{R, \text { stage }, A}(1)+Q_{R, \text { stage }}(1) \times C_{R, \text { stage, }}(1)}$

With:

$\mathrm{Q}_{\mathrm{R}, \text { stage }}(1)$ the retentate flowrate of the final stage (1) in the retentate retreatment section where the overall retentate of the cascade is recovered.

$C_{R, \text { stage,A }}(1)$ and $C_{R, \text { stage, } B}(1)$ the concentrations of $\mathbf{A}$ and $\mathbf{B}$, respectively, in the overall retentate of the cascade recovered on the final stage (1) in the retentate retreatment section.

The calculation is performed a first time starting from the target permeate and retentate purities, easily converted into mole fractions, to get the design of the cascade. Once the first design of the cascade is obtained, the calculation of the cascade performance is recalculated in order to check the mass balances of the whole cascade and to calculate the real permeate and retentate purities as well as the yields of recovery according to the simulated membrane cascade.

\subsubsection{Goal expressed in terms of yields of recovery}

If the goal of the separation is expressed in terms of yields of recovery in the final permeate and retentate (equations 16 and 17), an iterative procedure has to be performed for the calculation (Figure 10-a).

Permeate recovery for solute $A=\frac{Q_{P, \text { stage }}(1) \times C_{P, s t a g e, A}(1)}{Q_{F} \times C_{F, A}}$

With:

$Q_{F}$ the flowrate of the feed of the cascade.

$\mathrm{C}_{\mathrm{F}, \mathrm{A}}$ the concentration of $\mathbf{A}$ in the feed of the cascade.

Retentate recovery for solute $B=\frac{Q_{R, \text { stage }}(1) \times C_{R, \text { stage, }}(1)}{Q_{F} \times C_{F, B}}$

With: 
$\mathrm{C}_{\mathrm{F}, \mathrm{B}}$ the concentration of $\mathrm{B}$ in the feed of the cascade

To initiate the calculation, final purities of the two obtained fractions are a priori chosen as follows:

(i) the final retentate purity in $\mathbf{B}$ must be chosen close to but higher than the feed purity.

(ii) the final permeate purity in $\mathbf{A}$ must be chosen close to but higher than the feed purity.

(iii) the first cycle of calculation is achieved generating a first cascade design. If the cascade fulfills the goal of the separation, the method is stopped. If not, a new couple of target mole fractions in the final retentate and permeate is selected by increasing the mole fraction of $\mathbf{B}$ in the final retentate and lowering that of $\mathbf{B}$ in the final permeate. The calculation is performed following consecutive iterations until the separation goal is fulfilled (iteration step in mole fraction is 0.0002). Once the iterative procedure is achieved, the design of the cascade is found and the cascade performances re-estimated.

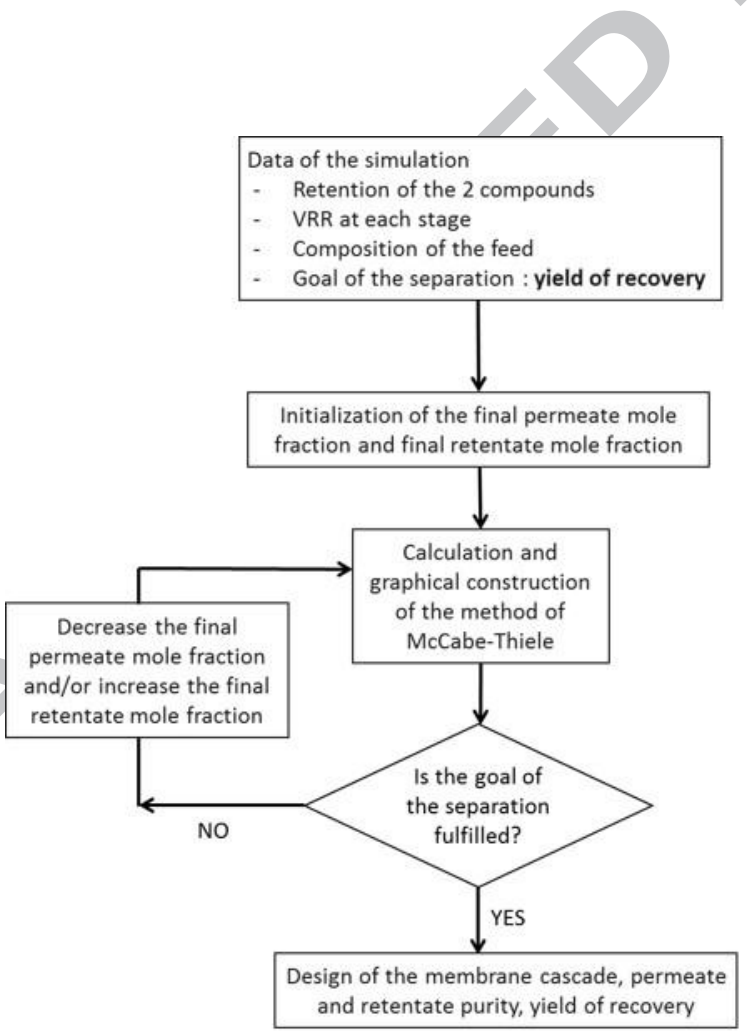

(a)

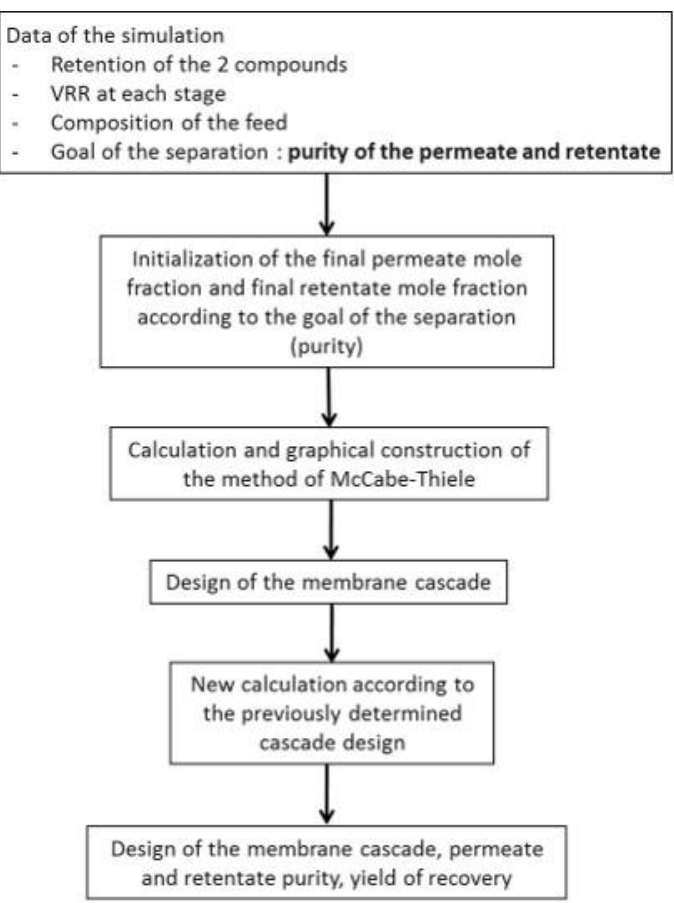

(b) 
Figure 10: Diagrams about the calculation of the method of McCabe-Thiele-(a): goal of the separation dealing with yield of recovery - (b) goal of the separation dealing with purity.

\section{Results and discussion}

The results are divided into two parts. First, a general discussion is proposed dealing with the impact of VRR and rejections. Second, a case study dealing with the olefin hydroformylation is proposed, developed with two approaches depending on the target criteria either in terms of purity or in terms of yield of recovery.

\subsection{1. Sensitivity analysis of the method according to choices of VRR and rejections}

In this paragraph, a general discussion is proposed to highlight the impact of initial choices, especially when dealing with $\mathrm{VRR}_{\text {stage }}$ and constant rejections on the McCabe-Thiele diagram.

\subsubsection{Influence of the VRR}

The partitioning curves depend on the $\mathrm{VRR}_{\text {stage, }}$ (Table 1, Figure 6, equations 4-8) as well as the operating lines (Table 1, Figure 6, equations 9-12).

In the case studied here, the variation of $V_{R R}$ stage is systematically tested in the range from 2 to 10. These variations have impacts whose strength depends on the curves or the operating lines, as it will be explained below. According to the application, the most interesting results concerns the higher values of $\mathrm{VRR}_{\text {stage, }}$, typically $\mathrm{VRR}_{\text {stage }}$ greater than 5 on which we have focused on the study.

\subsubsection{Partitioning curves versus VRR}

The higher is the $\mathrm{VRR}_{\text {stage, }}$, the farer is the partitioning curves from the first bisector meaning that the separation would be more efficient in terms of purity at higher VRR (Figure 11). However, at first sight the difference between the three partitioning curves obtained for VRRs 5,8 and 10 appears not very significant. 


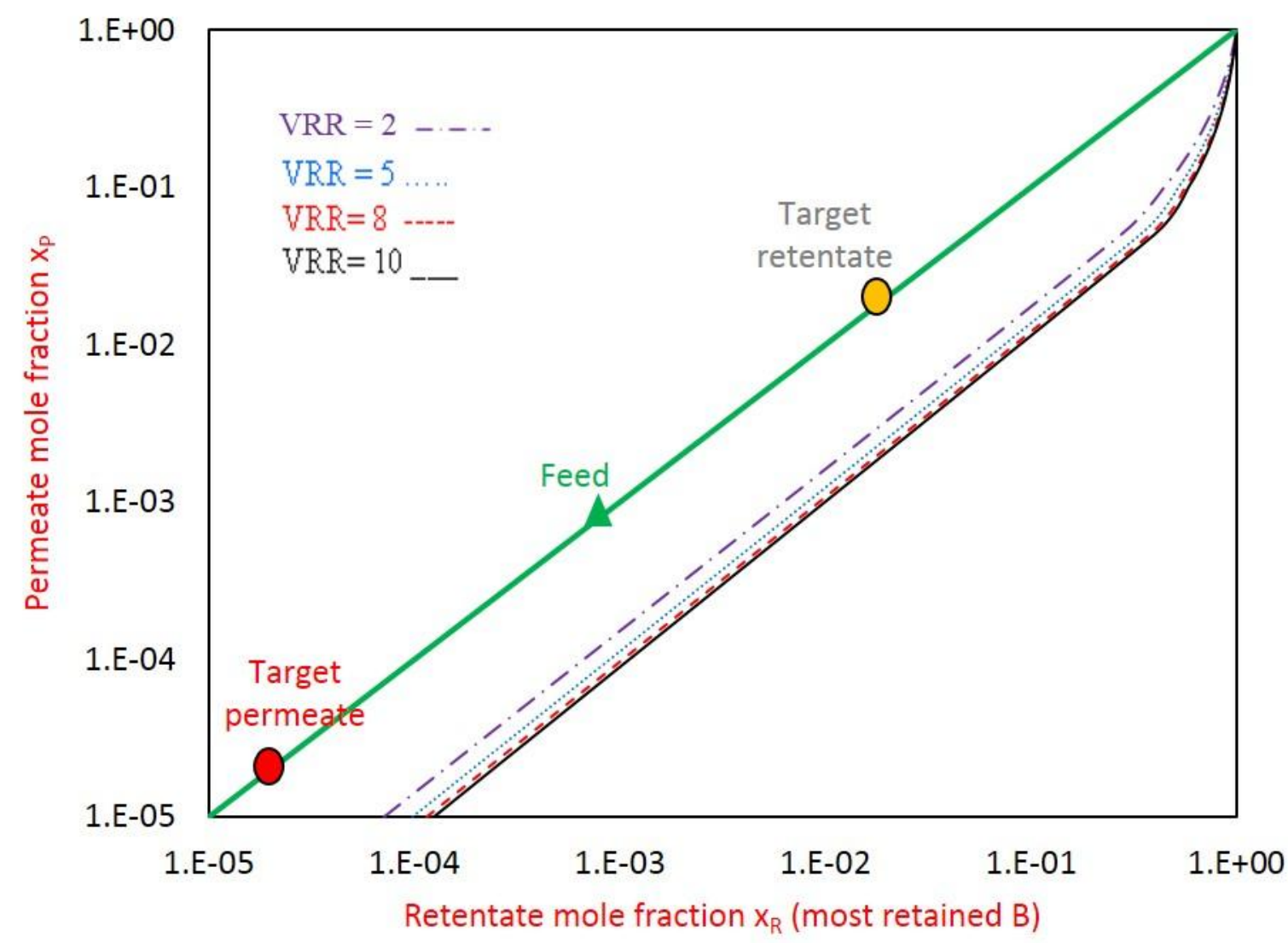

Figure 11- Partitioning curves depending on VRR in the case study of the OSN separation of $\boldsymbol{A}$ and $\boldsymbol{B}$ at 1 mol. $L^{-1}$ and $10^{-3}$ mol. $L^{-1}$ initial concentrations and $30 \%$ and $88 \%$ rejections, respectively.

\subsubsection{Operating lines of one stage versus VRR}

Figure 12-a,b,c show an example of three operating lines either in the retentate or in the permeate retreatment section, for different VRRs that are chosen similar for each stage of the entire cascade. In each cascade section, for a given VRR, when increasing the number of stage the operating lines become closer and closer to the first bisector meaning that the separation would be easier. In both sections, the difference in operating lines is more pronounced between the first two stages that are the further from stage 0 than for the following ones.

Figure 12-d,e,f show that for a given stage wherever in the cascade, the higher the VRR, the farer the operating lines of the retentate retreatment section are from the partitioning curve. This means that when the VRR increases, the "steps" in the graphical build-up are larger and so fewer stages are needed to perform the separation. A conclusion is more difficult to draw for the permeate retreatment section because both the partitioning curve and the operating lines recede from the first bisector when the VRR increases. 


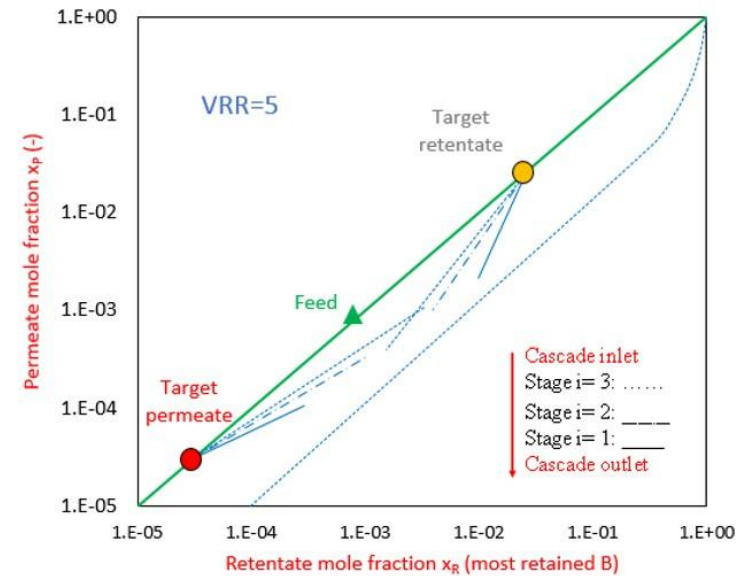

(a)

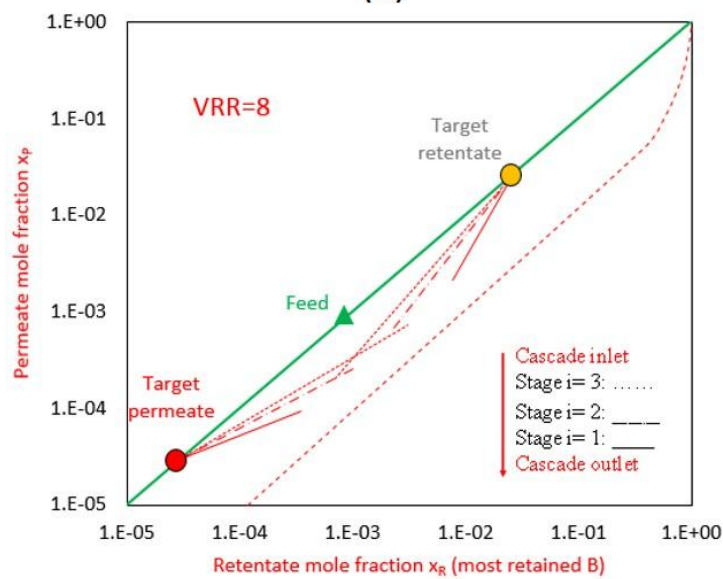

(b)

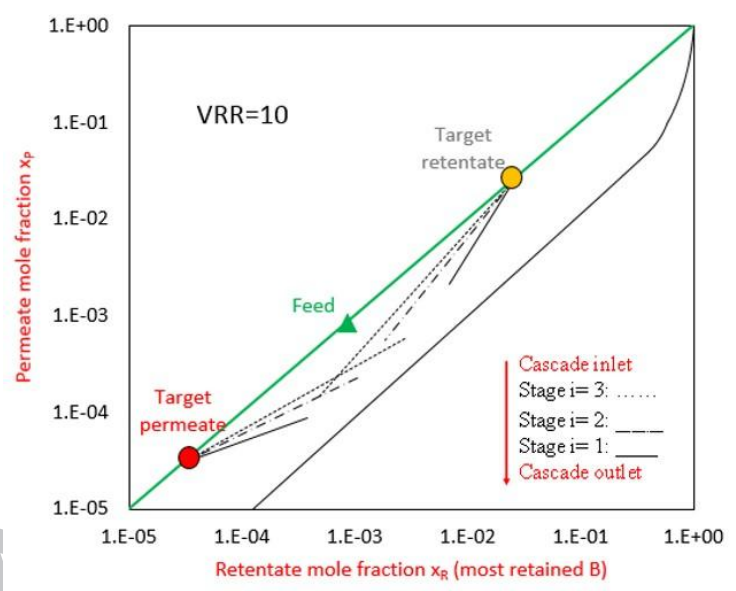

(c)

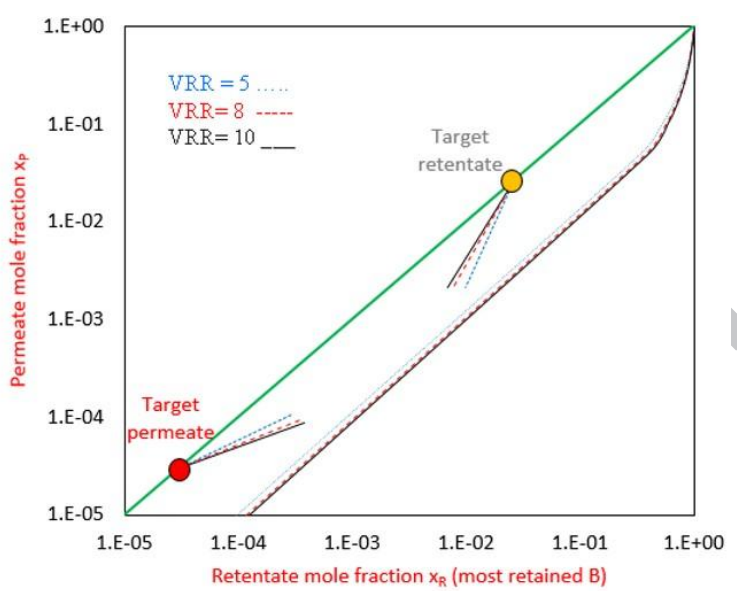

(d)

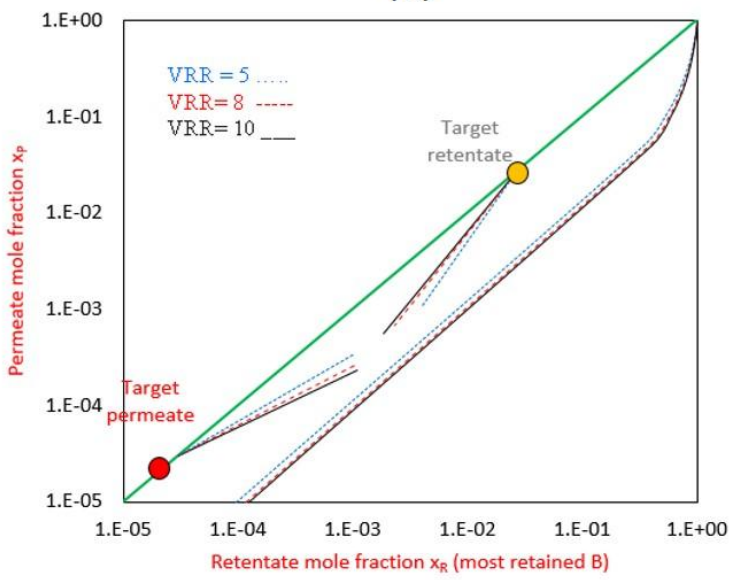

(e)

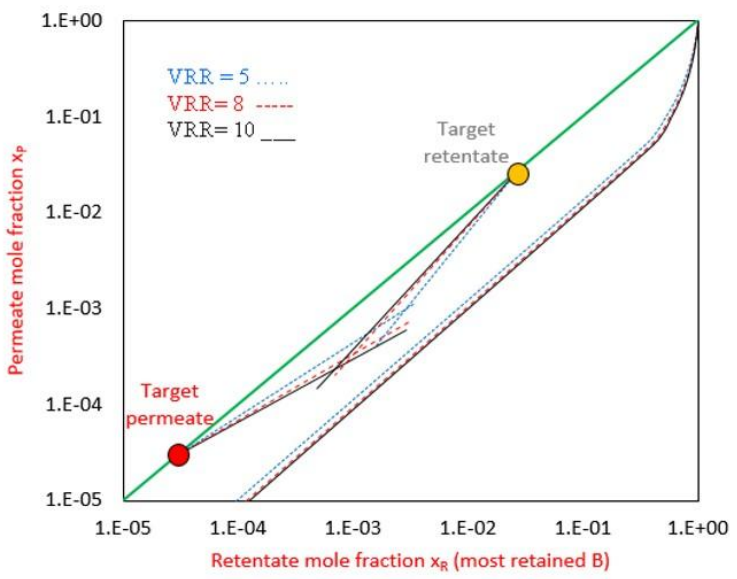

(f)

Figure 12: For a 3-stage cascade, operating lines in each cascade section depending on VRR in the case study of the OSN separation of $\boldsymbol{A}$ and $\boldsymbol{B}$ at 1 mol. $L^{-1}$ and $10^{-3}$ mol. $L^{-1}$ initial concentrations and $30 \%$ and $88 \%$ rejections, respectively - First 3 operating lines for constant VRR: (a) VRR $=5-(b) V R R=8-(c) V R R=10$ - Relative position of operating lines for: (d) stages +1 and -1 (outlet of the cascade) - (e) stages +2 and $-2-(f)$ stages +3 and -3 - see also Figure 13 and [48] for the stages nomenclature in the cascade. 


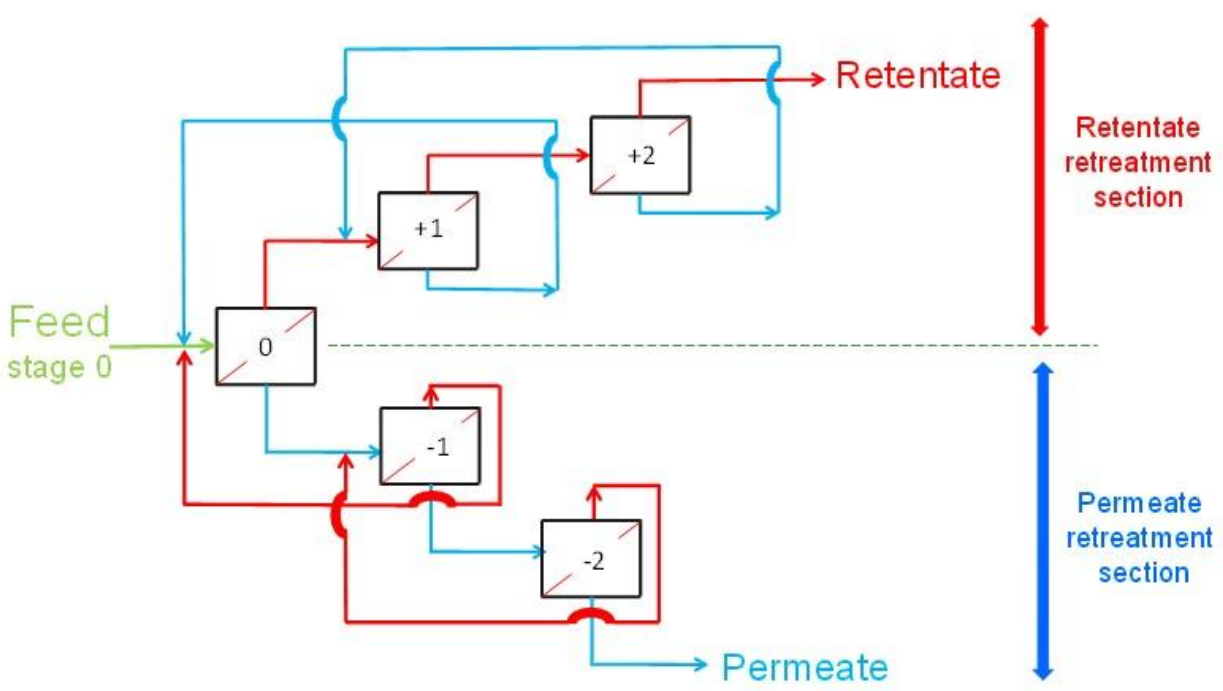

(a) $(+2-2)$ cascade

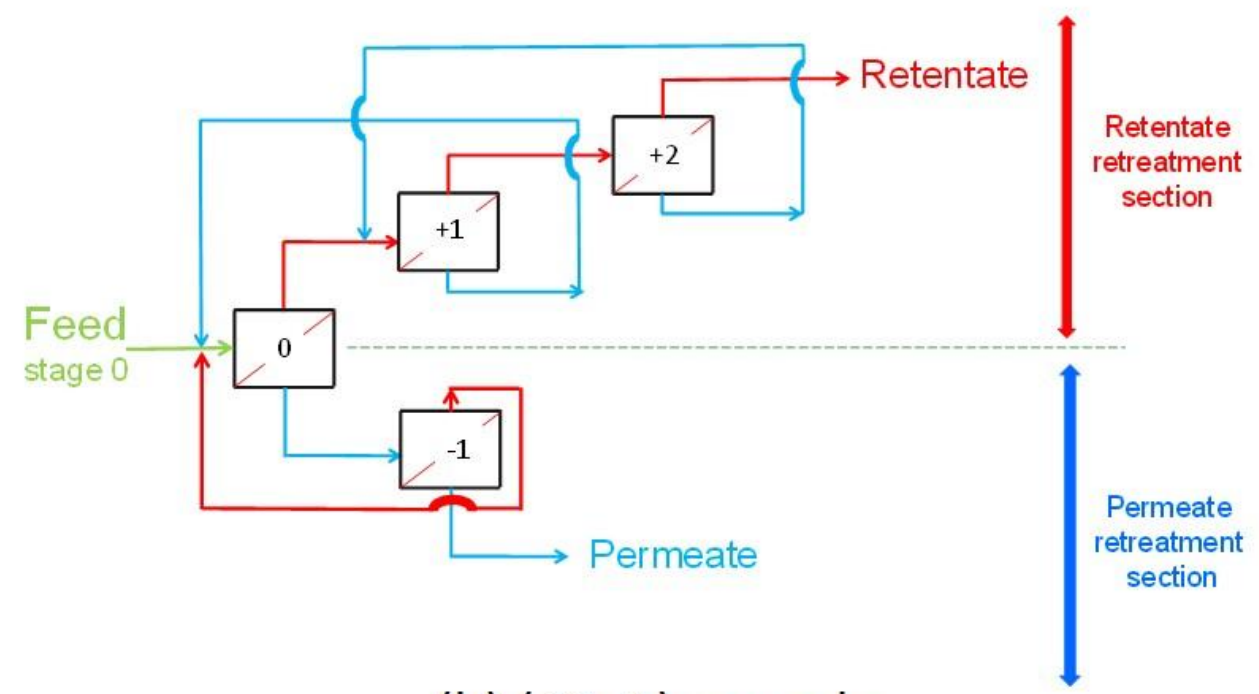

(b) (+2 -1) cascade

Figure 13: Nomenclature in the final cascade for which each stage is renamed in a systematic way with index either positive (retentate retreatment section) or negative (permeate retreatment section) [48] - (a) case of (+2 -2) cascade with 5 stages (2 in the retentate section: +2 (the further one from stage 0 , corresponding retentate is $x_{R},(1)$ in equation 9 ,

Figure 7-b), +1, feed stage 0, 2 in the permeate section: -1, -2 (the further one from stage 0 , corresponding permeate is $x_{P},(1)$ in equation 13, Figure 7-c ) - (b) case of a (+2 -1) cascade with 4 stages.

\subsubsection{Influence of the rejections}

Alternatively, variations in rejection of $\mathbf{A}$ and $\mathbf{B}$ have been studied, all other parameters being constant. This case can appear as slightly different from the case study of olefin hydroformylation but is nevertheless discussed here. 


\subsubsection{Variation of $\boldsymbol{B}$ rejection at constant $\boldsymbol{A}$ rejection}

Aiming at highlighting the impact of the rejections on the partitioning curves and operating lines on the McCabe-Thiele diagram, calculations have been made maintaining the solute $\mathbf{A}$ rejection to $30 \%$ but varying solute $\mathbf{B}$ rejection from $88 \%$ down to $50 \%$, i.e. lowering the rejection difference between the two solutes.

Figure 14-a shows, at VRR 10, the impact of this variation on the partitioning curve as well as on the operating lines for which only the first stage (the further from the feed stage) has been plotted. The rejection of $\mathbf{B}$ has a strong impact on the partitioning curve. The lower is the solute $\mathbf{B}$ rejection, the closer is the partitioning curve from the first bisector, and so the more difficult is the separation. This graphic is another way to judge if a membrane is appropriate for a given separation. Actually, if the partitioning curve is too close from the first bisector, the separation cannot be easily fulfilled. Thus comparison of the relative position of partitioning curves for several VRRs in given hydrodynamic conditions or for a given VRR with different hydrodynamic conditions can help to master the filtration with a given membrane or to select the best available membrane from a set of experiments. The operating lines positions are also modified. The higher is the solute $\mathbf{B}$ rejection, the farer are the operating lines from the partitioning curve, either that of the retentate retreatment section or that of the permeate retreatment section. It means that fewer stages are needed to perform the separation which is logical because the difference in rejections is higher and so the separation is easier.

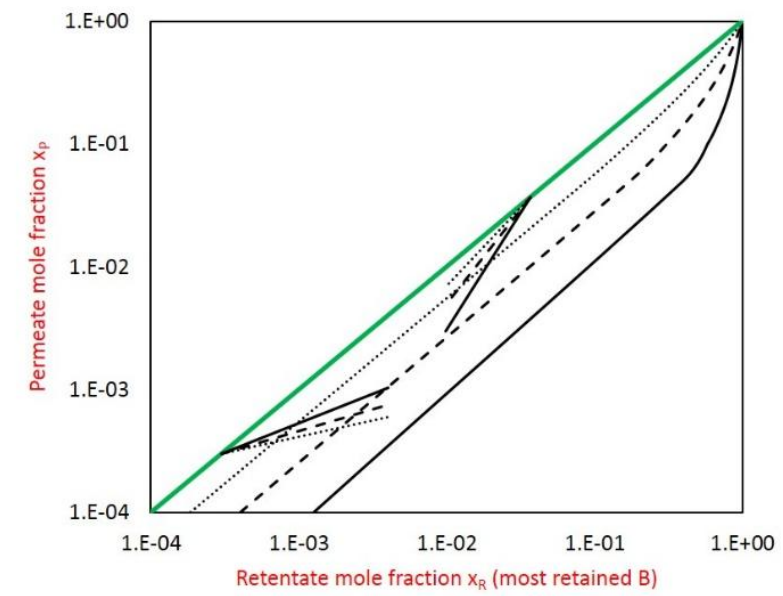

(a)

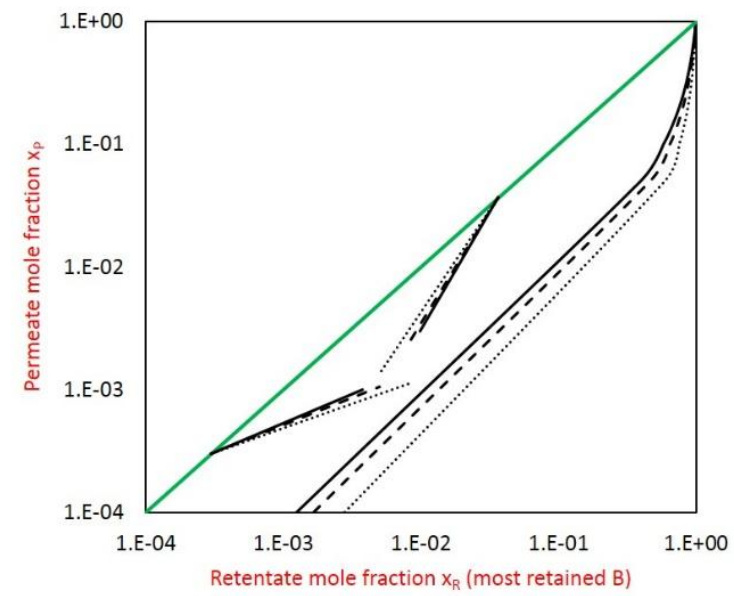

(b)

Figure 14: Impact of the rejections on the McCabe-Thiele diagram at VRR=10-(a) $\boldsymbol{A}$ rejection $30 \%$ and $\boldsymbol{B}$ rejection $50 \%$ (...) ; 70\% (---) ; 88\% (-) - (b) $\boldsymbol{B}$ rejection $88 \%$ and $\boldsymbol{A}$ rejection $30 \%(-) ; 20 \%(---) ; 0 \%(\ldots)$. 


\subsubsection{Variation of $\boldsymbol{A}$ rejection at constant high $\boldsymbol{B}$ rejection}

Aiming at highlighting the impact of the rejection on the curves and operating lines on the McCabe-Thiele diagram, calculations have been made maintaining the solute $\mathbf{B}$ rejection to $88 \%$ but varying the solute $\mathbf{A}$ rejection from $30 \%$ down to $0 \%$, i.e. increasing the rejection difference between the two solutes but maintaining quite high rejection of the solute to be retained whereas the solute to be transmitted passes more and more easily through the membrane. Figure 14-b shows, at VRR 10, the impact of this variation on the partitioning curve as well as on the operating lines for which only the first stage (the further from the feed stage) has been plotted. The A rejection has also a strong impact on the partitioning curve: the lower is the solute A rejection, the farer is the operating line from the first bisector which means that the separation would be easier. Moreover the lower is A rejection, the farer are the operating lines from the partitioning curve for both sections. It means that fewer stages will be needed to perform the separation that would be easier. Finally, to conclude on the impact of $\mathbf{A}$ rejections at VRR $=10$, Table 3 depicts the cascade inferred from the McCabe-Thiele diagrams. It can be drawn that the cascade configuration is not modified with respect to $\mathbf{A}$ rejection but the real efficiency of OSN might significantly evolve in a favourable way if $\mathbf{B}$ rejection remains quite constant and $\mathbf{A}$ rejection progressively decreases.

Table 3: Impact of $A$ rejection at $V R R=10$ on cascade designs inferred from McCabe-Thiele diagrams - initial feed $\boldsymbol{A}=99.90 \%$ and $\boldsymbol{B}$ purity $=0.10 \%$ - targets of OSN: $\boldsymbol{A}$ purity > $99.99 \%$ (permeate) and $\boldsymbol{B}$ purity $\geq 1.00 \%$ (retentate).

\begin{tabular}{|c|c|c|c|}
\hline \multicolumn{4}{|c|}{ Rejection (\%) } \\
\hline A & 0 & 20 & 30 \\
\hline B & \multicolumn{3}{|c|}{88} \\
\hline \multicolumn{4}{|c|}{ Cascade design } \\
\hline Number of stages & \multicolumn{3}{|c|}{3} \\
\hline Cascade configuration* & \multicolumn{3}{|c|}{$(+1-1)$} \\
\hline \multicolumn{4}{|c|}{ OSN performances } \\
\hline Extraction of A (\%) & 98.8 & 96.6 & 94.2 \\
\hline Purity of A in permeate (\%) & 99.991 & 99.99 & 99.99 \\
\hline Recovery of B (\%) & 90.8 & 90.8 & 90.8 \\
\hline Purity of $\mathrm{B}$ in retentate $(\%)$ & 6.93 & 2.58 & 1.53 \\
\hline
\end{tabular}




\subsection{Case study}

Users generally express their targets according to two ways:

$\circ$ purity of the obtained fractions (the yield of recovery appearing as a consequence of this main objective but of less interest)

$\circ$ yield of recovery (the purity of the product being a consequence of this main objective).

\subsubsection{Case study 1: target expressed in terms of purity with constant VRR $R_{\text {stage }}$}

The designed cascades must be able to recover two fractions of known purity in $\mathbf{A}$ or $\mathbf{B}$, namely:

○ in the permeate: A with a purity better than $99.99 \%$. This objective means that OSN would act as an extraction process of $\mathbf{A}$ from the synthesis medium but also as an advanced purification step.

$\circ$ In the retentate: $\mathbf{B}$ with a purity greater than $1.00 \%$. This target means that B would be 10 times more enriched than in the feed and that a huge amount of toluene passes through the membrane limiting the volume of retentate to recycle in the batch synthesis (that is a second requirement)

The target of the separation can be expressed as the mole fractions: $x_{P, B}=10^{-4}$ and $x_{R, B}=10^{-2}$. Note that in the feed A purity is $99.90 \%$ whereas $\mathbf{B}$ purity is $0.10 \%\left(\mathrm{x}_{\mathrm{F}, \mathrm{B}}=10^{-3}\right)$

Systematic simulations of a one-step OSN have been achieved with VRR varying from 2 to 10. None of them is able to fulfill the requirements (partial results are shown in Table 4). Then the McCabe-Thiele diagrams are calculated for several VRRs. For sake of illustration in the following, only the whole illustration for $\mathrm{VRR}=6$ will be given in details as well as comparison of results obtained for only 3 VRRs (VRR: 5, 6, 8).

The diagram of McCabe-Thiele for a one-stage process with VRR= 6 is shown in Figure 15-a and the build-up of the whole cascade in Figure 15-c.

Figure 13 shows some cascade designs inferred from Figure 15 and Table 4 sums up the overall calculated performances. The requirements are fulfilled for one cascade with four stages $(+2-1)$ running either at $\mathrm{VRR}_{\text {stage }}=6$ or 8 and one cascade with five stages $(+2-2)$ running at $\mathrm{VRR}_{\text {stage }}=5$. But clearly the recovery of $\mathbf{A}$ (respectively $\mathbf{B}$ ) is slightly different from one proposal to another. 
Table 4: Case study 1: cascade designs inferred from McCabe-Thiele diagrams of Figure 15 $(V R R=6)$ and equivalent Figures $(V R R=5,8$, not shown $)$ - initial feed $\boldsymbol{A}=99.90 \%$ and $\boldsymbol{B}$ purity $=0.10 \%$ - calculations with constant rejections $(30 \%$ for $\boldsymbol{A}$ and $88 \%$ for $\boldsymbol{B})$ - targets of OSN: A purity $>99.99 \%$ (permeate) and $\boldsymbol{B}$ purity $\geq 1.00 \%$ (retentate)

\begin{tabular}{|c|c|c|c|c|c|c|}
\hline VRR $_{\text {stage }}$ & 5 & 6 & 8 & 5 & 6 & 8 \\
\hline \multicolumn{7}{|c|}{ Cascade designs } \\
\hline $\begin{array}{l}\text { Number of } \\
\text { stages }\end{array}$ & \multicolumn{3}{|c|}{1} & 5 & 4 & 4 \\
\hline $\begin{array}{c}\text { Cascade } \\
\text { configuration* }\end{array}$ & \multicolumn{3}{|c|}{ (0) } & $(+2-2)$ & $(+2-1)$ & $(+2-1)$ \\
\hline \multicolumn{7}{|c|}{ Separation performances } \\
\hline $\begin{array}{c}\text { Extraction of A } \\
(\%)\end{array}$ & 67.6 & 71.5 & 76.7 & 90.1 & 94.6 & 97.4 \\
\hline $\begin{array}{l}\text { Purity of } A \text { in } \\
\text { permeate }(\%)\end{array}$ & 99.974 & 99.973 & 99.97 & 99.999 & 99.994 & 99.992 \\
\hline $\begin{array}{c}\text { Recovery of B } \\
(\%)\end{array}$ & 82.4 & 80.7 & 77.9 & 99.1 & 94.3 & 92.1 \\
\hline $\begin{array}{l}\text { Purity of B in } \\
\text { retentate }(\%)\end{array}$ & 0.25 & & 0.33 & 1.00 & 1.72 & 3.47 \\
\hline $\begin{array}{l}\text { Enrichment of } \\
\mathrm{B} \text { in retentate }\end{array}$ & & 2.8 & 3.3 & 10.0 & 17.2 & 34.7 \\
\hline Global VRR & 5 & 6 & 8 & 65 & 130 & 350 \\
\hline \multicolumn{7}{|c|}{ Consumption for 10,000 ton per year of $\mathbf{A}$} \\
\hline $\begin{array}{c}\text { Membrane area } \\
\left(\mathrm{m}^{2}\right)\end{array}$ & 304 & 318 & 337 & 1645 & 1037 & 975 \\
\hline $\mathrm{W}_{\mathrm{OSN}}(\mathrm{kW})$ & 3.0 & 3.0 & 3.0 & 14.6 & 8.8 & 8.0 \\
\hline
\end{tabular}

What about the realism of such cascade designs? The detailed discussion of the results is out of the scope of this paper and only some slight comments are given below dealing with the quality of the proposal. First, the global VRR can probably be used for discrimination since too high values are probably not practically reachable. Second, to make a decision other parameters have to be taken into account among which the required filtering area and the energy consumption will have an important role. For first and partial illustration only, such calculations are achieved considering a production involving 10,000 ton per year of $\mathbf{A}$ to be 
treated by OSN. The needed energy $\left(\mathrm{W}_{\mathrm{OSN}}\right)$ and membrane area $\left(\mathrm{A}_{\mathrm{mb}}\right)$ are estimated from the following set of equations:

$\mathrm{W}_{\mathrm{OSN}}(\mathrm{kW})=\sum_{\mathrm{i}} \frac{\mathrm{TMP} \times \mathrm{Q}_{\mathrm{F}, \text { stage } \mathrm{i}}}{\eta_{\text {pump }}}$

With

$\mathrm{Q}_{\mathrm{F}, \text { stage i }}$ the feed flowrate of stage $\mathrm{i}$

$\eta_{\text {pump }}$ the pump efficiency, chosen equal to 0.7 .

$A_{m b}\left(m^{2}\right)=\sum_{i} \frac{Q_{P, \text { stage } i}}{L_{P, \text { stage }} \times T M P}$

With :

$\mathrm{Q}_{\mathrm{p} \text {,stage i }}$ the permeate flowrate of stage $\mathrm{i}$ at room temperature

$\mathrm{L}_{\mathrm{P} \text {,stage } \mathrm{i}}$ the membrane permeance $\left(\mathrm{L} \cdot \mathrm{m}^{-2} \cdot \mathrm{h}^{-1} \cdot \mathrm{bar}^{-1}\right)$ at stage $\mathrm{i}$ at room temperature, being calculated according to experimental data [47] corresponding to :

$\mathrm{L}_{\mathrm{P}, \text { stage } \mathrm{i}}=0.178 \times \overline{\mathrm{C}_{\mathrm{R}, \text { stage } \mathrm{i}}}(\mathbf{A})^{2}-0.996 \times \overline{\mathrm{C}_{\mathrm{R}, \text { stage } \mathrm{i}}}(\mathbf{A})+2.934$

When $\overline{\mathrm{C}_{\mathrm{R}, \text { stage }}}(\mathrm{A})<2.5 \mathrm{~mol} . \mathrm{L}^{-1}$

and

$\mathrm{L}_{\mathrm{P}, \text { stage i }}=-0.1 \times \overline{\mathrm{C}_{\mathrm{R} \text {,stage } \mathrm{i}}}(\mathrm{A})+1.8$

When $\overline{\mathrm{C}_{\mathrm{R}, \text { stage } \mathrm{i}}}(\mathrm{A})>2.5 \mathrm{~mol} . \mathrm{L}^{-1}$

With:

$\overline{\mathrm{C}_{\mathrm{R}, \text { stage }}}(\mathbf{A})$ the average concentration of $\mathbf{A}\left(\mathrm{mol} \cdot \mathrm{L}^{-1}\right)$ at stage $\mathrm{i}$.

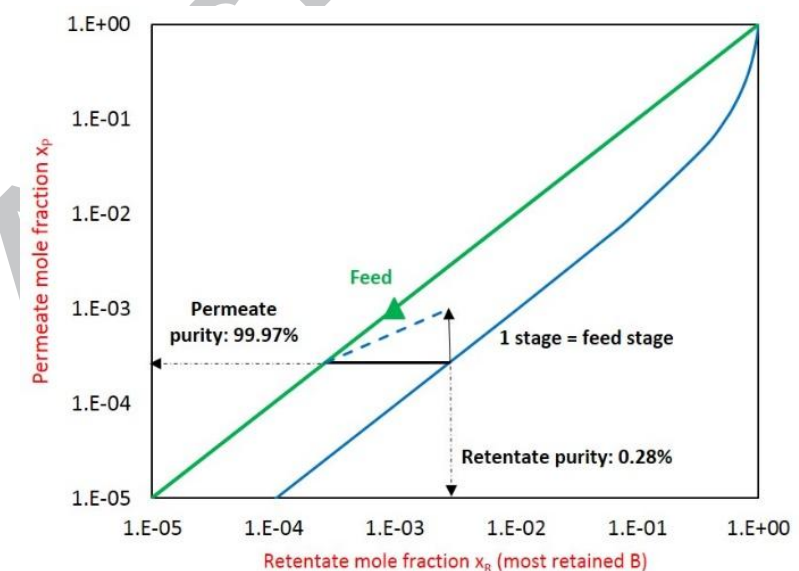

(a)

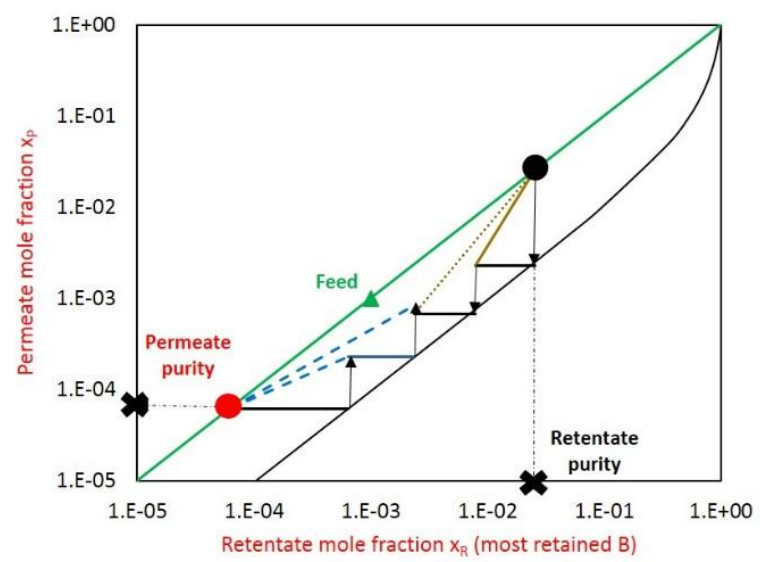

(b)

Figure 15: Case study 1: diagram of McCabe-Thiele at VRR=6 
$\boldsymbol{\Delta}:$ feed composition; $\boldsymbol{x}$ : goals of the separation $)-($ a) one-stage process $(-$ : partitioning curve ; - --: operating lines for the permeate retreatment section) - (b) overall cascade(-: partitioning curve ; - --: operating lines for the permeate retreatment section ; '... : operating line for the retentate retreatment section).

4.2.2. Case study 2: target expressed in terms of recovery with constant $V R R_{\text {stage }}$

The cascade designs must be able to recover two fractions of initially unknown purity in $\mathbf{A}$ or $\mathbf{B}$, the main objective concerning $\mathbf{B}$ :

0 in the retentate: more than $99 \%$ of $\mathbf{B}$ must be recovered. This requirement is compatible with the catalytic system management knowing that the metal precursor and the extra free ligand are both very expensive and must be recycled several times in the synthesis reactor. In this case the purity of $\mathbf{B}$ is not a determining parameter because $\mathbf{A}$ is not able to poison the reaction.

$\circ$ in the permeate: more than $70 \%$ of $\mathbf{A}$ must be recovered mainly to overcome its accumulation in the synthesis reactor, the volume of which being limited and must be used for addition of fresh substrate to transform and not occupied by $\mathbf{A}$ for sake of productivity.

The target of the separation cannot be easily expressed by the mole fractions: $\mathrm{X}_{\mathrm{P}, \mathrm{B}}$ and and $\mathrm{X}_{\mathrm{R}, \mathrm{B}}$. But as explained in Figure 10 the calculation must be initiated, then iterations occur.

Systematic simulations of a one-step OSN have been achieved with VRR 2 to 10. None of them is able to fulfill the requirements (partial results are shown in Table 5). Then the McCabe-Thiele diagrams have been calculated for several VRRs. For sake of illustration in the following only the whole illustration for $\mathrm{VRR}=5$ will be given in details as well as the comparison of results obtained for only three $\operatorname{VRRs}(\mathrm{VRR}=5,8,10)$.

The diagram of McCabe-Thiele and the build-up of the final whole cascade is shown in Figure 16 for $\mathrm{VRR}=5$. Table 5 gives the overall calculated performances. 


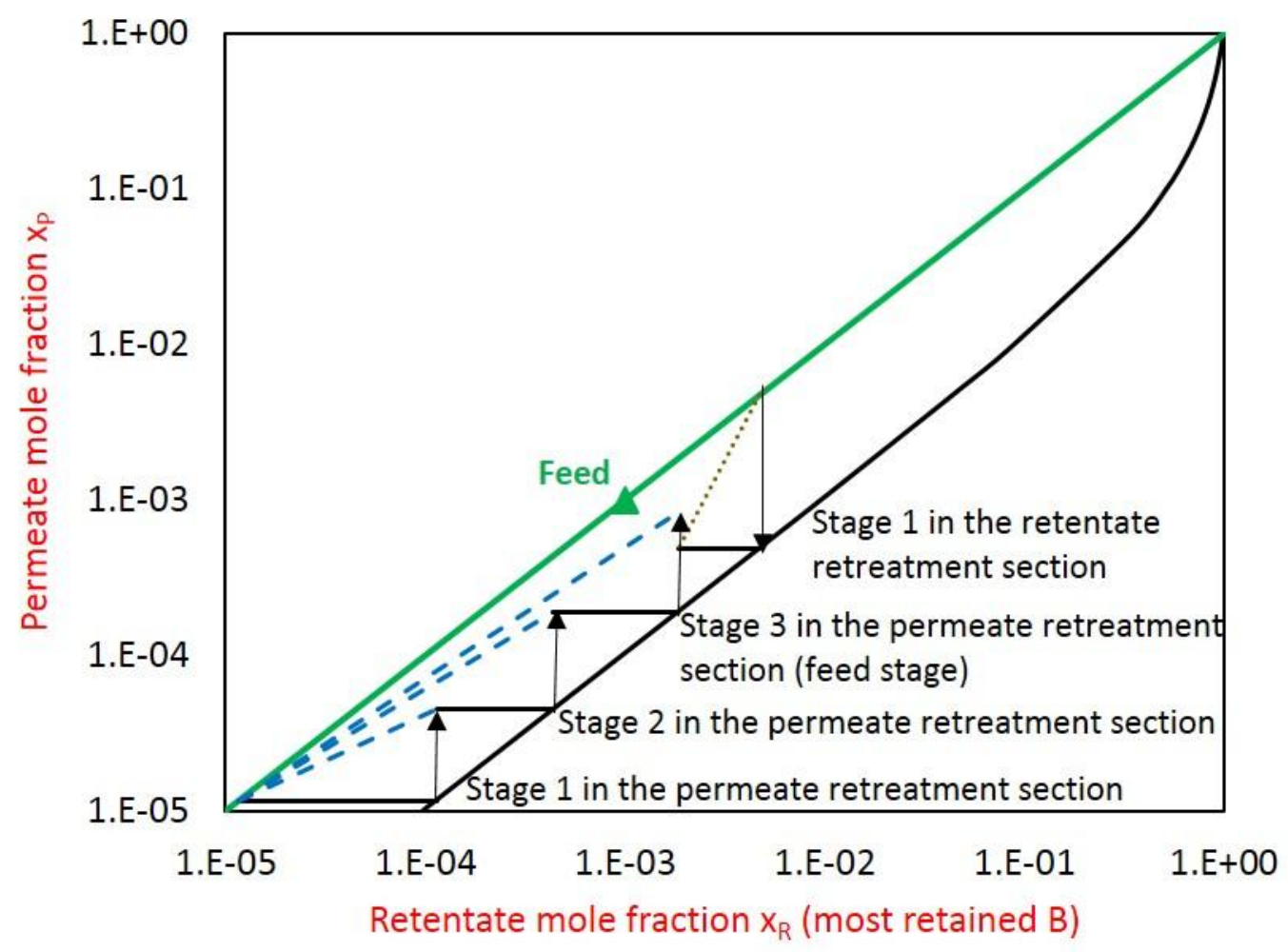

Figure 16: Diagram of McCabe-Thiele (VRR=5 at each stage) dealing with more than 99\% of solute $\boldsymbol{B}$ retentate recovery and more than $70 \%$ of solute $\boldsymbol{A}$ permeate extraction (-: partitioning curve ; - --: operating lines for the permeate retreatment section ; $\cdots$ : operating line for the retentate retreatment sections ; $\mathbf{\Delta}$ : feed composition).

The requirements are fulfilled for three very different configurations: $(+1-2),(+1-3)$ and $(0$ 3). However, clearly the purity of $\mathbf{A}$ (respectively $\mathbf{B}$ ) is slightly different from one proposal to another. As already discussed in the case study 1, the global VRR, membrane area and energy consumption can be used for a first discrimination dealing with the realism of such designed cascades. 
Table 5: Case study 2: cascade designs inferred from McCabe-Thiele diagrams of Figure 16 $(V R R=5)$ and equivalent Figures $(V R R=8,10$, not shown $)$ - initial feed purities $\boldsymbol{A}=99.90 \%$ and $\boldsymbol{B}=0.10 \%$ - calculations with constant rejections (30\% for $\boldsymbol{A}$ and $88 \%$ for $\boldsymbol{B})$ - targets of OSN: $\boldsymbol{B}$ recovery $>99.0 \%$ (retentate) and $\boldsymbol{A}$ recovery $\geq 70 \%$ (permeate).

\begin{tabular}{|c|c|c|c|c|c|c|}
\hline $\mathrm{VRR}_{\text {stage }}$ & 5 & 8 & 10 & 5 & 8 & 10 \\
\hline \multicolumn{7}{|c|}{ Initiation of calculation } \\
\hline $\mathrm{X}_{\mathrm{P}, \mathrm{B}}$ & \multicolumn{3}{|c|}{ none } & $3 \mathrm{E}-05$ & $3 \mathrm{E}-05$ & $3 \mathrm{E}-05$ \\
\hline $\mathrm{x}_{\mathrm{R}, \mathrm{B}}$ & \multicolumn{3}{|c|}{ none } & $1.998 \mathrm{E}-03$ & $1.998 \mathrm{E}-03$ & $1.998 \mathrm{E}-03$ \\
\hline \multicolumn{7}{|c|}{ Iteration performed } \\
\hline $\begin{array}{l}\text { Number of } \\
\text { iterations }\end{array}$ & \multicolumn{3}{|c|}{ none } & 79 & 232 & 20 \\
\hline \multicolumn{7}{|c|}{ Cascade designs } \\
\hline $\begin{array}{l}\text { Number of } \\
\text { stages }\end{array}$ & \multicolumn{3}{|c|}{1} & 4 & 5 & 4 \\
\hline $\begin{array}{c}\text { Cascade } \\
\text { configuration }\end{array}$ & \multicolumn{3}{|c|}{0} & $(+1-2)$ & $(+1-3)$ & $(0-3)$ \\
\hline & & & & 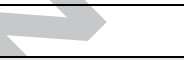 & & \\
\hline \multicolumn{7}{|c|}{ OSN performances } \\
\hline $\begin{array}{c}\text { Extraction of A } \\
(\%)\end{array}$ & 67.6 & 76.7 & 80.0 & 79.0 & 90.8 & 75.1 \\
\hline $\begin{array}{l}\text { Purity of A in } \\
\text { permeate (\%) }\end{array}$ & 99.974 & 99.971 & 99.970 & 99.999 & 99.999 & 99.999 \\
\hline $\begin{array}{c}\text { Recovery of B } \\
(\%)\end{array}$ & 82.4 & 77.9 & 75.9 & 99.1 & 99.4 & 99.3 \\
\hline $\begin{array}{l}\text { Purity of B in } \\
\text { retentate }(\%)\end{array}$ & 0.25 & & 0.38 & 0.47 & 1.07 & 0.40 \\
\hline $\begin{array}{l}\text { Enrichment of } \\
\text { B in retentate }\end{array}$ & 2.5 & 3.3 & 3.8 & 4.7 & 10.7 & 4.0 \\
\hline Global VRR & 5 & 8 & 10 & 16 & 49 & 9 \\
\hline \multicolumn{7}{|c|}{ Consumption for 10,000 ton per year of $\mathbf{A}$} \\
\hline $\begin{array}{c}\text { Membrane area } \\
\left(\mathrm{m}^{2}\right)\end{array}$ & 304 & 337 & 348 & 1465 & 1881 & 1534 \\
\hline $\mathrm{W}_{\text {OSN }}(\mathrm{kW})$ & 3.0 & 3.0 & 3.0 & 13.5 & 15.5 & 12.9 \\
\hline
\end{tabular}

\section{Conclusion}

In this paper, several membrane cascade designs are discussed according to a set of reasonable selected targets, also aiming at the determination of possible separation goals reachable with only membrane cascades (knowing that combined processes involving membranes could be discussed sometimes in a more realistic way).

Starting from an analogy with distillation processes, the method of McCabe-Thiele, initially proposed to design distillation columns, has been adapted to a first attempt of the rational 
design of membrane cascades useful for the OSN separation of media issued from olefin hydroformylation. The method allows designing membrane cascades according to separation goals expressed in terms of permeate and retentate purity or yield of recovery, thanks to only slight modifications to do the calculations.

The main difference between distillation and membrane is due to the number of partitioning curves as well as the operating lines to play with. From a set of three curves/lines deduced from thermodynamic data at a given pressure for distillation, the adaptation to membranes requires, for constant given rejections of $\mathbf{A}$ and $\mathbf{B}$ to separate, a set of partitioning curves per VRR as well as a set of operating lines per VRR, per stage and per retreatment section, for only one membrane used in given hydrodynamic conditions and a single pressure. When only modifying the rejections of the two solutes, all curves/lines are also modified increasing the complexity of the overall McCabe-Thiele diagram. Depending on the respective rejections of $\mathbf{A}$ and $\mathbf{B}$, the impact would be more or less pronounced. The use of the method appears then quite complicated when considering the number of curves/lines to play with, but quite simple when dealing with the graphical build-up itself. Thus the user can imagine very different situations at OSN start among which (for a given membrane in given conditions) the more reasonable would be to play with VRR at each stage and to take into account the natural and general evolution of the rejections with the concentration increase.

With respect to the chosen case study that can be extended to other interesting cases for fine chemistry, several a priori simplifications are suggested. Among them:

- The choice of the two most appropriate solutes in the mixture to be separated on which the cascades can be firstly designed, before a more accurate analysis.

- The need in an argued choice of $\mathrm{VRR}_{\text {stage }}$ when calculating all curves/operating lines. A first choice can be made by considering (in order of importance):

- the maximum VRR that can be used at industrial scale in order to avoid unfeasible proposals. Such choice is not easy to do, but dealing with our case study it seems to be mainly ruled by dead volume of OSN equipment rather than viscosity or osmotic pressure. Our choice is to avoid VRR higher than 10.

- the position of the partitioning curve toward the first bisector. The farer they are the fewer stages are generated. 
- the position of the operating lines (in each retreatment section). The farer the operating lines from the partitioning curve the simpler and more efficient is the cascade configuration.

- The choice of the constant rejection level used for calculations. Here is chosen the case for which the difference in rejection of $\mathbf{A}$ and $\mathbf{B}$ is the greater one reachable in starting conditions (OSN on the final synthesis medium) together with a quite high rejection of the solute to retain in the retentate (B, "optimal TMP”). Finally, in a real OSN filtration at the selected pressure, this choice is the less favourable situation encountered in this system; because during concentration (VRR increase) the difference in $\mathbf{A}$ and $\mathbf{B}$ rejections increases but that of $\mathbf{B}$ decreases only a little whereas that of $\mathbf{A}$ falls down. Therefore, the present method of McCabe-Thiele could be used as a first approach with constant rejection to judge the feasibility of the OSN separation (if too many stages are needed the separation cannot be done with the chosen membrane and operating conditions, see also discussion about global VRR) and to identify promising membrane cascades. The cascades inferred from such calculations corresponds then to a kind of "limit cascades" or in other words the most complicated cascades to discuss before simplification and optimization, the latter being drawn for instance from systematic simulations to improve the precision of the separation before pilot scale tests.

Moreover, such McCabe-Thiele graph as well as above enounced rules can help choose the best couple (hydrodynamic conditions, pressure) for a given membrane or to make a choice between several membranes working in similar hydrodynamic and pressure conditions or, probably better, when they are working in their own best conditions.

Finally as perspective, the next milestone for adaptation to membrane cascades would be to have a global McCabe-Thiele diagram based on a continuous variation of the rejection according to the mixture composition. Such a change would modify the partitioning curve(s) and the operating lines. Nowadays, the main identified difficulty is that the method works with mole fraction while the rejection would vary according to the mole fraction and the concentration too. Once again, the lack of global model allowing simulation of transfer mechanisms and their consequences is an important limitation to further developments of membrane process simulation. 


\section{Acknowledgements}

The french National Agency for Research (ANR - France) is acknowledged for the financial support of the MemChem project $\mathrm{n}^{\circ}$ ANR-14-CE06-0022.

The French clusters IAR and Axelera are thanked for labelling the MemChem project.

\section{References}

[1] P. van der Gryp, A. Barnard, J.-P. Cronje, D. de Vlieger, S. Marx, H.C.M. Vosloo, Separation of different metathesis Grubbs-type catalysts using organic solvent nanofiltration, J. Membr. Sci. 353 (2010) 70-77.

[2] M.S. Shaharun, M.F. Taha, Nanofiltration of rhodium tris(triphenylphosphine) catalyst in ethyl acetate solution, International Conference on Fundamental and Applied Sciences 2012. AIP Conf. Proc. 1482 (2012) 279-283.

[3] S. Aerts, A. Buekenhoudt, H. Weyten, L.E.M. Gevers, I.F.J. Vankelecom, P.A. Jacobs, The use of solvent resistant nanofiltration in the recycling of the Co-Jacobsen catalyst in the hydrolytic kinetic resolution (HKR) of epoxides, J. Membr. Sci. 280 (2006) 245252.

[4] M. Rabiller-Baudry, G. Nasser, T. Renouard, D. Delaunay, M. Camus, Comparison of two nanofiltration membrane reactors for a model reaction of olefin metathesis achieved in toluene, Sep. Purif. Technol. 116 (2013) 46-60.

[5] J.M. Dreimann, F. Hoffmann, M. Skiborowski, A. Behr, A.J. Vorholt, Merging Thermomorphic Solvent Systems and Organic Solvent Nanofiltration for Hybrid Catalyst Recovery in a Hydroformylation Process, Ind. Eng. Chem. Res. 56 (2017) 1354-1359.

[6] D. Nair, J.T. Scarpello, L.S. White, L.M. Freitas dos Santos, I.F.J. Vankelecom, A.G. Livingston, Semi-continuous nanofiltration-coupled Heck reactions as a new approach to improve productivity of homogeneous catalysts, Tetrahedron Lett. 42 (2001) 82198222.

[7] P. Vandezande, L.E.M. Gevers, I.F.J. Vankelecom, Solvent resistant nanofiltration: separating on a molecular level, Chem. Soc. Rev. 37 (2008) 365-405.

[8] A. Datta, K. Ebert, H. Plenio, Nanofiltration for Homogeneous Catalysis Separation: Soluble Polymer-Supported Palladium Catalysts for Heck, Sonogashira, and Suzuki Coupling of Aryl Halides, Organometallics. 22 (2003) 4685-4691.

[9] D. Nair, S.S. Luthra, J.T. Scarpello, L.S. White, L.M. Freitas dos Santos, A.G. Livingston, Homogeneous catalyst separation and re-use through nanofiltration of organic solvents, Desalination. 147 (2002) 301-306.

[10] A. Keraani, T. Renouard, C. Fischmeister, C. Bruneau, M. Rabiller-Baudry, Recovery of enlarged olefin metathesis catalysts by nanofiltration in an eco-friendly solvent, ChemSusChem. 1 (2008) 927-933.

[11] A. Keraani, M. Rabiller-Baudry, C. Fischmeister, C. Bruneau, Immobilisation of an ionically tagged Hoveyda catalyst on a supported ionic liquid membrane: An innovative approach for metathesis reactions in a catalytic membrane reactor, Catal. Today. 156 (2010) 268-275. 
[12] G. Nasser, T. Renouard, S. Shahane, C. Fischmeister, C. Bruneau, M. Rabiller-Baudry, Interest of the Precatalyst Design for Olefin Metathesis Operating in a Discontinuous Nanofiltration Membrane Reactor, ChemPlusChem. 78 (2013) 728-736.

[13] A. Keraani, M. Rabiller-Baudry, C. Fischmeister, D. Delaunay, A. Baudry, C. Bruneau, T. Renouard, First elaboration of an olefin metathesis catalytic membrane by grafting a Hoveyda-Grubbs precatalyst on zirconia membranes, Comptes Rendus Chim. (2017).

[14] N.J. Ronde, D. Totev, C. Müller, M. Lutz, A.L. Spek, D. Vogt, Molecular-weightenlarged multiple-pincer ligands: synthesis and application in palladium-catalyzed allylic substitution reactions, ChemSusChem. 2 (2009) 558-574.

[15] H.P. Dijkstra, G.P.M. van Klink, G. van Koten, The Use of Ultra- and Nanofiltration Techniques in Homogeneous Catalyst Recycling, Acc. Chem. Res. 35 (2002) 798-810.

[16] M. Janssen, J. Wilting, C. Müller, D. Vogt, Continuous Rhodium-Catalyzed Hydroformylation of 1-Octene with Polyhedral Oligomeric Silsesquioxanes (POSS) Enlarged Triphenylphosphine, Angew. Chem. Int. Ed. 49 (2010) $7738-7741$.

[17] P. Wijkens, J.T.B.H. Jastrzebski, P.A. van der Schaaf, R. Kolly, A. Hafner, G. van Koten, Synthesis of Periphery-Functionalized Dendritic Molecules Using Polylithiated Dendrimers as Starting Material, Org. Lett. 2 (2000) 1621-1624.

[18] D. Schoeps, V. Sashuk, K. Ebert, H. Plenio, Solvent-Resistant Nanofiltration of Enlarged (NHC)Pd(allyl)Cl Complexes for Cross-Coupling Reactions, Organometallics. 28 (2009) 3922-3927.

[19] A. Kajetanowicz, J. Czaban, G.R. Krishnan, M. Malińska, K. Woźniak, H. Siddique, L.G. Peeva, A.G. Livingston, K. Grela, Batchwise and continuous nanofiltration of POSS-tagged Grubbs-Hoveyda-type olefin metathesis catalysts, ChemSusChem. 6 (2013) 182-192.

[20] J. Vanneste, D. Ormerod, G. Theys, D. van Gool, B. van Camp, S. Darvishmanesh, B. van der Bruggen, Towards high resolution membrane-based pharmaceutical separations, J. Chem. Technol. Biotechnol. 88 (2013) 98-108.

[21] S. Darvishmanesh, L. Firoozpour, J. Vanneste, P. Luis, J. Degrève, B. van der Bruggen, Performance of solvent resistant nanofiltration membranes for purification of residual solvent in the pharmaceutical industry: experiments and simulation, Green Chem. 13 (2011) 3476-3483.

[22] L.S. White, A.R. Nitsch, Solvent recovery from lube oil filtrates with a polyimide membrane, J. Membr. Sci. 179 (2000) 267-274.

[23] V.S.K. Adi, M. Cook, L.G. Peeva, A.G. Livingston, B. Chachuat, Optimization of OSN Membrane Cascades for Separating Organic Mixtures, in: Z.K. and M. Bogataj (Ed.), Comput. Aided Chem. Eng., Elsevier, 2016: 379-384.

[24] C. Abels, F. Carstensen, M. Wessling, Membrane processes in biorefinery applications, J. Membr. Sci. 444 (2013) 285-317.

[25] P. Marchetti, M.F. Jimenez Solomon, G. Szekely, A.G. Livingston, Molecular Separation with Organic Solvent Nanofiltration: A Critical Review, Chem. Rev. 114 (2014) 10735-10806.

[26] W.L. Peddie, J.N. van Rensburg, H.C.M. Vosloo, P. van der Gryp, Technological evaluation of organic solvent nanofiltration for the recovery of homogeneous hydroformylation catalysts, Chem. Eng. Res. Des. 121 (2017) 219-232.

[27] J. Dreimann, P. Lutze, M. Zagajewski, A. Behr, A. Górak, A.J. Vorholt, Highly integrated reactor-separator systems for the recycling of homogeneous catalysts, Chem. Eng. Process. Process Intensif. 99 (2016) 124-131.

[28] Z. Xie, G.R. Akien, B.R. Sarkar, B. Subramaniam, R.V. Chaudhari, Continuous Hydroformylation with Phosphine-Functionalized Polydimethylsiloxane Rhodium 
Complexes as Nanofilterable Homogeneous Catalysts, Ind. Eng. Chem. Res. 54 (2015) 10656-10660.

[29] E.J. O’Neal, K.F. Jensen, Continuous Nanofiltration and Recycle of a Metathesis Catalyst in a Microflow System, ChemCatChem. 6 (2014) 3004-3011.

[30] D. Ormerod, B. Bongers, W. Porto-Carrero, S. Giegas, G. Vijt, N. Lefevre, D. Lauwers, W. Brusten, A. Buekenhoudt, Separation of metathesis catalysts and reaction products in flow reactors using organic solvent nanofiltration, RSC Adv. 3 (2013) 21501-21510.

[31] Nur S. A. Razak, Maizatul S. Shaharun, Hilmi Mukhtar, Mohd F. Taha, Separation of hydridocarbonyltris(triphenylphosphine) rhodium (I)catalyst using solvent resistant nanofiltration membrane, Sains Malays. 42 (2013) 515-520.

[32] M. Priske, K.-D. Wiese, A. Drews, M. Kraume, G. Baumgarten, Reaction integrated separation of homogenous catalysts in the hydroformylation of higher olefins by means of organophilic nanofiltration, J. Membr. Sci. 360 (2010) 77-83.

[33] A. Caus, L. Braeken, K. Boussu, B. van der Bruggen, The use of integrated countercurrent nanofiltration cascades for advanced separations, J. Chem. Technol. Biotechnol. 84 (2009) 391-398.

[34] W.E. Siew, A.G. Livingston, C. Ates, A. Merschaert, Continuous solute fractionation with membrane cascades - A high productivity alternative to diafiltration, Sep. Purif. Technol. 102 (2013) 1-14.

[35] I. Soroko, M.P. Lopes, A. Livingston, The effect of membrane formation parameters on performance of polyimide membranes for organic solvent nanofiltration (OSN): Part A. Effect of polymer/solvent/non-solvent system choice, J. Membr. Sci. 381 (2011) 152162.

[36] P. Ahmadiannamini, X. Li, W. Goyens, B. Meesschaert, I.F.J. Vankelecom, Multilayered PEC nanofiltration membranes based on SPEEK/PDDA for anion separation, J. Membr. Sci. 360 (2010) 250-258.

[37] K. Hendrix, M. Vaneynde, G. Koeckelberghs, I.F.J. Vankelecom, Synthesis of modified poly(ether ether ketone) polymer for the preparation of ultrafiltration and nanofiltration membranes via phase inversion, J. Membr. Sci. 447 (2013) 96-106.

[38] N. Joseph, P. Ahmadiannamini, R. Hoogenboom, I.F.J. Vankelecom, Layer-by-layer preparation of polyelectrolyte multilayer membranes for separation, Polym. Chem. 5 (2014) $1817-1831$.

[39] A.K. Hołda, B. Aernouts, W. Saeys, I.F.J. Vankelecom, Study of polymer concentration and evaporation time as phase inversion parameters for polysulfone-based SRNF membranes, J. Membr. Sci. 442 (2013) 196-205.

[40] J. Fang, R. Jana, J.A. Tunge, B. Subramaniam, Continuous homogeneous hydroformylation with bulky rhodium catalyst complexes retained by nano-filtration membranes, Appl. Catal. Gen. 393 (2011) 294-301.

[41] W.E. Siew, A.G. Livingston, C. Ates, A. Merschaert, Molecular separation with an organic solvent nanofiltration cascade - augmenting membrane selectivity with process engineering, Chem. Eng. Sci. 90 (2013) 299-310.

[42] R. Abejón, A. Garea, A. Irabien, Analysis and optimization of continuous organic solvent nanofiltration by membrane cascade for pharmaceutical separation, AIChE J. 60 (2014) 931-948.

[43] R. Abejón, A. Garea, A. Irabien, Optimum design of reverse osmosis systems for hydrogen peroxide ultrapurification, AIChE J. 58 (2012) 3718-3730.

[44] R. Abejón, A. Abejón, A. Garea, T. Tsuru, A. Irabien, M.P. Belleville, J. SanchezMarcano, In Silico Evaluation of Ultrafiltration and Nanofiltration Membrane Cascades for Continuous Fractionation of Protein Hydrolysate from Tuna Processing Byproduct, Ind. Eng. Chem. Res. 55 (2016) 7493-7504. 
[45] J. Vanneste, S. De Ron, S. Vandecruys, S.A. Soare, S. Darvishmanesh, B. van der Bruggen, Techno-economic evaluation of membrane cascades relative to simulated moving bed chromatography for the purification of mono- and oligosaccharides, Sep. Purif. Technol. 80 (2011) 600-609.

[46] A. Lejeune, T. Renouard, M. Rabiller-Baudry, Simulation of membrane cascades for the separation of 2 solutes of intermediate rejections by organic solvent nanofiltration, poster at OSN conference, June 4-6, 2017, St Petersburg, Russia.

[47] A. Lejeune, Nanofiltration organique appliquée à l'hydroformylation des oléfines dans le toluène. Étude expérimentale, conception et simulation de cascades. (Organic solvent nanofiltration applied to olefin hydroformylation in toluene. Experimental study, design and simultion of cascades) Thèse de doctorat de l'université de Rennes 1, France, 2017.

[48] T. Renouard, A.Lejeune, M. Rabiller-Baudry, Separation of solutes with an organic solvent nanofiltration cascade: designs, simulations and systematic study of all configurations, Sep. Purif. Technol. 194 (2018) 111-122.

[49] J.C.-T. Lin, A.G. Livingston, Nanofiltration membrane cascade for continuous solvent exchange, Chem. Eng. Sci. 62 (2007) 2728-2736.

[50] W.L. McCabe, E.W. Thiele, Graphic Design of Fractionating Columns, Ind. Eng. Chem. 17 (1925) 605-611.

[51] R. Ravi, A rigorous analysis of McCabe-Thiele assumptions and their consequences: critical role of parallel enthalpy lines, Chem. Eng. Commun. 193 (2006) 55-68.

[52] M. Hadadian, M.H. Mallah, M.A. Moosavian, J. Safdari, M. Davoudi, Separation of uranium (VI) using dispersive liquid-liquid extraction from leach liquor, Prog. Nucl. Energy. 90 (2016) 212-218.

[53] S.-T. Hwang, K. Kammermeyer, Operating lines in cascade separation of binary mixtures, Can. J. Chem. Eng. 43 (1965) 36-39.

[54] S.-T. Hwang, K. Kammermeyer, Membranes in Separations, John Wiley \& Sons, NY, USA, 1975.

[55] J.T.F. Keurentjes, L.J.M. Linders, W.A. Beverloo, K. Van't Riet, Membrane cascades for the separation of binary mixtures, Chem. Eng. Sci. 47 (1992) 1561-1568.

[56] J.B. Haelssig, J. Thibault, A.Y. Tremblay, Numerical investigation of Membrane Dephlegmation: A hybrid pervaporation-distillation process for ethanol recovery, Chem. Eng. Process. Process Intensif. 50 (2011) 1226-1236.

[57] P. Luis, J. Degrève, B.V. der Bruggen, Separation of methanol-n-butyl acetate mixtures by pervaporation: Potential of 10 commercial membranes, J. Membr. Sci. 429 (2013) 112.

[58] M.S. Avgidou, S.P. Kaldis, G.P. Sakellaropoulos, Membrane cascade schemes for the separation of LPG olefins and paraffins, J. Membr. Sci. 233 (2004) 21-37.

[59] M. Mulder, Basic Principles of Membrane Technology, 2 E, Springer, Netherlands, 1996.

[60] Dow Chemicals, FILMTECH Reverse Osmosis Membranes - Technical Manual, https://dowac.custhelp.com/app/answers/detail/a_id/3428/ /filmtec-membranes--filmtecs-technical-manual available online Dec. 2017.

[61] L. Peeva, J. da Silva Burgal, I. Valtcheva, A.G. Livingston, Continuous purification of active pharmaceutical ingredients using multistage organic solvent nanofiltration membrane cascade, Chem. Eng. Sci. 116 (2014) 183-194.

[62] M.V. Rane, R. Sadanandam, K. Bhattacharya, S.K. Tangri, A.K. Suri, Use of mixedmetals isotherm and $\log -\log$ McCabe Thiele's diagram in solvent extraction-A case study, Hydrometallurgy. 81 (2006) 1-8. 